\title{
El arca en el mobiliario de la Asturias preindustrial: piezas del concejo de Grado
}

\author{
Chests in Asturian preindustrial furniture: \\ pieces from the concejo of Grado
}

\author{
Gerardo Díaz Quirós \\ Universidad de Oviedo
}

\section{RESUMEN}

Con la idea de contribuir al conocimiento del mobiliario en la Asturias preindustrial se estudia un conjunto de arcas del concejo asturiano de Grado. Previo repaso al papel jugado por esta tipología en el mobiliario asturiano y a sus características básicas, tanto estructurales como decorativas, se ofrece análisis más pormenorizado de una selección de piezas representativas.

Palabras clave: Mueble popular, Asturias, Ebanistería, Motivos decorativos.

\section{SUMMARY}

With the intention of contributing to knowledge of preindustrial Asturian furniture, the author studies a group of chests from the concejo of Grado. He establishes the role played by this typology in Asturian furniture and its basic characteristics, structural as well as decorative, and then presents a detailed analysis of a selection of representative pieces.

Key words: Traditional Furniture, Asturias, Cabinetmaking, Decorative Motifs.

En la sencillez extrema de su estructura, el arca ha sido uno de los muebles más presentes en el ajuar doméstico a lo largo del tiempo, de la geografía o de las clases sociales. En Asturias, donde se mantuvo hasta bien entrado el siglo xx como el mueble más rico de la vivienda en amplias zonas de su territorio, goza en la actualidad de especial prestigio, hasta el punto de ser, probablemente, la pieza más identificada con lo vernáculo y por tanto objeto de reproducciones y reinterpretaciones. A pesar de todo, el conocimiento que se tiene del arca es sumario y dista mucho de sus posibilidades interpretativas. Los cambios operados en el mundo rural asturiano en la 
segunda mitad del siglo Xx afectaron - como no podía ser de otra formaal mobiliario tradicional, que se vio relegado frente a nuevos tipos y materiales, pasando muchas piezas, en el mejor de los casos, al mercado de antigüedades. Casonas y palacios vieron desperdigados con frecuencia sus enseres con ocasión de reformas y cambios de uso. Sin duda son muchas las piezas que se han perdido o se consumen en el abandono, pero se cuentan también por cientos las que continúan amueblando espacios y sirviendo en el fondo al mismo fin esencial para el que fueron concebidas.

\section{EL CONOCIMIENTO DEL MUEBLE EN ASTURIAS}

Si el interés por el estudio del mueble español arranca en el último tercio del siglo XIX, citándose la fecha de 1879 y a Juan Facundo Riaño como punto de partida en el ámbito de las publicaciones (Aguiló 1993: 9), apenas ha tenido desarrollo esta parcela de la investigación en el caso de Asturias ${ }^{1}$. Tan sólo algunos muebles de la Catedral de Oviedo (Ramallo 1999: 270-286) y los que forman la colección de la familia Selgas Fagalde (González 1998: 101-161) han sido objeto de atención detenida en fecha relativamente reciente. En lo que respecta a lo que se viene llamando "mueble popular" la fortuna no ha sido mayor. Entre los investigadores que se aproximaron en las primeras décadas del siglo Xx al mundo popular con frecuencia las referencias al mobiliario o el ajuar doméstico resultan más una evocación literaria - amparada en un conocimiento directo de la realidad, obtenido mediante numerosas visitas o consecuencia del trabajo de campo desarrollado en el transcurso de otros estudios- que el fruto de una investigación sistemática (Cabal 1931; de Llano 1922); línea que se mantuvo, aunque con otro carácter en fechas más recientes (Lago 1988; Mases 1994)².

A través de los datos aportados por diversos informantes - cita expresamente el autor los facilitados por M. Menéndez García y L. RodríguezCastellano- así como a partir de la consulta de las obras de Constantino Cabal, de la monografía de Martínez Torner sobre Llanuces y de estudios lingüísticos como el de María Josefa Canellada sobre el bable de Cabranes, el de Martínez Neira sobre el habla de Lena, el de J. A. Fernández sobre Sisterna o el de Rodríguez Castellano sobre el vocabulario del bable occidental, algunos datos sobre el mueble popular en Asturias se incorporan a

\footnotetext{
${ }^{1}$ Para una aproximación a la historiografía del mueble español ver Moya (1990).

${ }^{2}$ La vía abierta en los años 30 con algunos estudios monográficos sobre enseres muy concretos (Ferreiro 1931; Artiñano 1935) fue apenas seguida, volcándose los trabajos en el ámbito del folklore en el mundo de las mentalidades o la cultura inmaterial.
} 
la colosal obra de Fritz Krüger (1963) sobre el mobiliario popular en los países románicos.

Si ya en 1946 Julio Caro Baroja señalara en una nota de su libro, Los pueblos de España la inexistencia de un estudio sobre las arcas asturianas y el interés del mismo, L. M. Feduchi — autor de la compilación sobre mueble español más seguida durante décadas - le anotaba a Krüger para esta publicación (1963: 56) que:

Merecería este mueble un estudio especial por su enorme difusión y permanencia. Todavía en España en casi todas las casas populares, rústicas o burguesas provincianas, es tal la abundancia de arcas con diversos usos, formas y calidades que pueden contarse por docenas.

El propio Krüger (1963: 1, 2) repara en la riqueza decorativa de algunos de estos muebles, por más que no se considere la persona adecuada para llevar a término su estudio y análisis. "La decoración artística del arca — escribe- ha originado en muchos países una variedad tal de estilos y motivos que este aspecto, por importante que sea, debe ser reservado a los especialistas en obras de arte". Más adelante (1963: 5) al referirse a las tipologías insiste en que "sería interesante seguir en detalle esta última fase de la evolución vinculada con la historia de los estilos de arte y sus manifestaciones en los diversos países".

La publicación en castellano del texto de Krüger no supuso, sin embargo, el estímulo definitivo para iniciar un trabajo en Asturias que se aproximase por lo menos a algunas de las monografías citadas en la abundantísima bibliografía compilada por el filólogo de Spremberg.

Por lo que tiene - lamentablemente- de excepción consideramos relevante la aparición en 1984 del catálogo de la colección etnográfica del Museo Arqueológico Provincial (Escortell 1984: 81-92). Si bien las propias características de la colección condicionaban en buena medida el estudio - entre otras cosas se desconoce la procedencia de la mayoría de las piezas- y el resultado pone en evidencia el escasísimo conocimiento que se tenía en ese momento del mueble en Asturias, el propio esfuerzo de catalogación contribuye a la dignificación de las piezas ${ }^{3}$. Y para refrendar el carácter excepcional de este catálogo sirva con anotar que ninguno de los museos asturianos que conserva algún número importante de muebles incorporados a sus colecciones — sea de la amplia Red de Museos Etnográficos de Asturias

${ }^{3}$ La colección del Museo Arqueológico tiene como núcleo básico las piezas donadas en 1951 por los herederos de D. Manuel González-Longoria Leal, Marqués de la Rodriga, viéndose acrecentada por las adquisiciones que José Fernández Buelta había realizado por indicación de la Diputación Provincial para la creación de un frustrado museo etnográfico. En el trabajo citado se catalogan un total de 42 piezas de mobiliario. 
o de otro ámbito - ha dado a la imprenta hasta el momento catalogación de esas piezas ${ }^{4}$.

La mayor aportación al conocimiento del mobiliario popular asturiano llegará de manos de Juaco López Álvarez y Armando Graña García. Vinculados desde finales de la década de los 70 del siglo xx a los estudios etnográficos, iniciaron, con escasos apoyos y justo cuando en el ámbito rural asturiano los cambios comenzaban a ser vertiginosos, una serie de estudios sobre aspectos de la cultura material que resultaron de extraordinaria relevancia desde distintas perspectivas. Trabajar con método, conceder importancia extrema al trabajo de campo, al estudio del objeto o la estructura en su contexto mientras fuese posible, atender a la información de base documental pero también a la tradición oral, sistematizar; aplicar en definitiva a esta parcela las reglas de la investigación en casi cualquier otra disciplina supuso alcanzar resultados del máximo interés. Particular trascendencia tuvieron sus estudios sobre hórreos y paneras y las manifestaciones artísticas aplicadas sobre ellos 5 , a partir de los cuales fue posible perfilar de forma solvente una historia y evolución del hórreo, definir sus características estructurales y poner de relieve la riqueza de sus decoraciones rescatando la figura de talleres, carpinteros y entalladores. La localización de cartelas labradas o pintadas con fechas y autorías obligó a revisar conceptos como el de anonimato o atemporalidad asociados a lo etnográfico o a lo popular.

Como se ha apuntado, fruto del intenso trabajo de campo realizado y de su interés por las manifestaciones artísticas populares fueron algunos breves artículos que se convirtieron durante décadas en los materiales de referencia para quién pretendiese una mínima aproximación al mobiliario en la región (Lopez y Graña 1986 y 1988b). En colaboración publicaron dos entregas de "Materiales para el estudio del mobiliario en Asturias", centrada la primera en una tipología específica como es la de las arcas de tres llaves

\footnotetext{
${ }^{4}$ Por su relación directa con este trabajo y a modo de ejemplo, quede anotado que el Museo Etnográfico de Grado no contaba en el momento de redactar estas notas más que con un documento referido en su título como "Descripción de los fondos que constituyen la colección del Museo Etnográfico de Grado" y que en su introducción se presenta como "inventario" de los fondos a 3 de marzo de 2005. Consta de 27 páginas en las que los fondos museográficos se organizan por espacios expositivos, dándoles un número correlativo y una identificación mínima. "Arca pequeña tallada", "Arca grande tallada" o "Arcón tallado" son los términos empleados para referirse a las piezas objeto de nuestro interés, sin más descripción y sin elemento gráfico de apoyo alguno.

5 No consideramos oportuno ofrecer relación completa de las publicaciones al respecto, pero se recogen en la bibliografía final dos de referencia: su trabajo sobre los hórreos y paneras del concejo de Allande y una aproximación al arte y los artistas populares en los hórreos y paneras de Asturias (Lopez y Graña 1983 y 1985).
} 
y la segunda en las arcas con decoración tallada. Reconociendo el "suficiente interés como para ser objeto de un estudio más detenido” prometían abordar un trabajo sobre el arca "en fecha no muy lejana", pero sin que llegase a verificarse.

Su reivindicación del interés del estudio del mueble y la voluntad de dignificación del llamado arte popular se ha ido materializando en otro tipo de reseñas o recapitulaciones que, por integrarse en proyectos editoriales de enorme difusión, han sido ciertamente importantes para el desarrollo del aprecio a las piezas y por tanto para su conservación (López y Graña 1988a, 1996, 2005).

Siguiendo su estela, atendiendo especialmente a la necesidad que reconocían de "hacer catálogos de los muebles que aún pueden localizarse en el campo" como medio para "conocer las características particulares de las distintas áreas de la región" y aprovechando también el conocimiento de la carpintería y la ebanistería de un área concreta proporcionado por el estudio exhaustivo de los hórreos y paneras de la zona, así como de las técnicas y motivos decorativos (Díaz 2001) publicamos unas notas sobre arcas decoradas en el concejo de Gozón ensayando cronologías y justificando atribución de autoría para algunas piezas (Díaz 2005)7.

Resulta evidente que el estudio del mueble en cualquiera de sus manifestaciones exige la localización y estudio de ejemplares conservados sobre los que volcar cuantos datos indirectos puede aportar la consulta documental o la evocación literaria. Desde estas premisas venimos realizando algunas campañas de localización y estudio de muebles por distintas áreas de Asturias. Los resultados más relevantes del trabajo en una de estas zonas conforman, precisamente, la última parte de este artículo.

\section{ARCa, arcón, arcona. DenOminación, tipologías y funciones}

En la nota preliminar a su Historia del Mueble Luis Feduchi señala al arca como uno de los cuatro tipos originarios a partir de los cuales cabría hacer derivar a todos los muebles ${ }^{8}$. Sobre los problemas de nomenclatura y clasi-

\footnotetext{
${ }^{6}$ Ya Jorge Aragoneses (1954: 607), en una línea similar aunque de mayor radio, había subrayado la importancia de la publicación "de ejemplares encontrados en las diferentes provincias, si se quiere ir elaborando un inventario de éstas y al mismo tiempo contribuir a la formación del catálogo general de las artes de la madera en España".

7 Una revisión más detenida del estado de la cuestión de la historia del mueble popular en Asturias puede verse en Díaz (2007: 307-322).

8 "Puede decirse que todos los muebles derivan de cuatro tipos originarios que acompañan al hombre desde los albores de su inteligencia social: la silla, la mesa, el arca y
} 
ficación ahonda Aguiló Alonso (1993: 81-95) que le dedica al arca un amplio capítulo en su trabajo sobre el mueble español de los siglos XVI y XVII, obra de referencia para el estudio del mueble en España. Señala que "de la utilización del arca como principal mueble de contener desde la Edad Media se derivaron sus diferentes tipos y materiales, según las funciones a que estaba destinada", precisando que "las diferentes denominaciones encontradas en los inventarios y las fuentes documentales, arca, cofre, baúl, se deben más a diferencias conceptuales de los propios escribanos, que a modismos regionales o locales" ". Aguiló (1993: 70) recuerda igualmente la clásica división que, siguiendo a Eames, distingue entre arcas con cubierta plana y patas que aíslan el contenido del suelo y las que descansan directamente sobre el suelo y presenten tapa curva, mejor adaptadas a las condiciones del viaje. Subraya, además — completando con una fundamentación de uso la de esencialidad estructural apuntada por Feduchi- que "en una época en que la movilidad y la seguridad de los bienes constituía la consideración primordial, la adaptabilidad del arca, en sus formas más variadas hicieron de ella el artículo más indispensable"10.

En Asturias las voces arca, arcón o arcona, remiten al mismo modelo tipológico, caracterizado por una forma de paralelepípedo conformado por tablas enterizas engarzadas por cola de milano en los $\operatorname{costados}^{11}$ —a veces reforzadas con clavos de hierro-, con el fondo clavado y tapa practicable en la parte superior por medio de bisagras de goncios (anillas enlazadas) y cerradura en el frente. Suele presentar patas cortas, en ocasiones formadas por dos travesaños colocados hacia los extremos, del mismo fondo que el mueble y que reciben algún trabajo en el extremo que ha de verse en el frontal. Sólo excepcionalmente las arcas localizadas en Asturias presentan faldones decorados. Cuando reciben trabajo de talla — frecuentemente las arcas

la cama" (Feduchi 1986: 7) Aunque la primera edición es de 1949, citaremos por la edición de 1986.

${ }^{9}$ El apartado dedicado a las arcas en el capítulo IV de este trabajo es una de las más completas revisiones generales sobre este mueble, constituyendo una referencia básica de inicio para estudios locales o para contextualizar el fenómeno de producciones populares.

${ }^{10}$ En su tesis doctoral Aguiló (1993) dedica un capítulo específico a los gremios de carpinteros y ebanistas en España. A partir de los documentos citados se pueden precisar numerosas cuestiones de nomenclatura; se habla, por ejemplo durante siglos de cofreros para quienes se dedican a la confección de arcas, baúles y cofres — segregándose en la Sevilla del siglo XIV la voz bauleros- o de guarnicioneros para quienes fabrican estuches y maletas, entre otros ejemplos.

${ }^{11}$ No es raro, sobre todo en piezas del siglo xviII encontrarse medias columnillas torneadas tapando estos ensambles en los frentes. 
que ocupaban lugares preeminentes de la casa, concebidas por tanto para ser vistas, salvo en las tierras del interior de la zona occidental de Asturias, donde no parece que llegase a extenderse tal costumbre- éste se centra en el frente principal, rara vez en los costados y nunca en la tapa o la trasera ${ }^{12}$. Salvo para responder a funciones muy concretas - arcas de cofradías que se utilizan también como cepillos petitorios, por ejemplo- los interiores no presentan divisiones, aunque sí es frecuente un cajoncillo adosado a uno de los costados con tapa móvil encajada y que se conoce como estoyu. Nogal y en mucha mayor medida castaño serán las maderas más utilizadas para su confección. Será el tamaño el que lleve a ha2blar de "arcón" o "arcona" para los de gran formato, aunque no exclusivamente (Fig. 1).

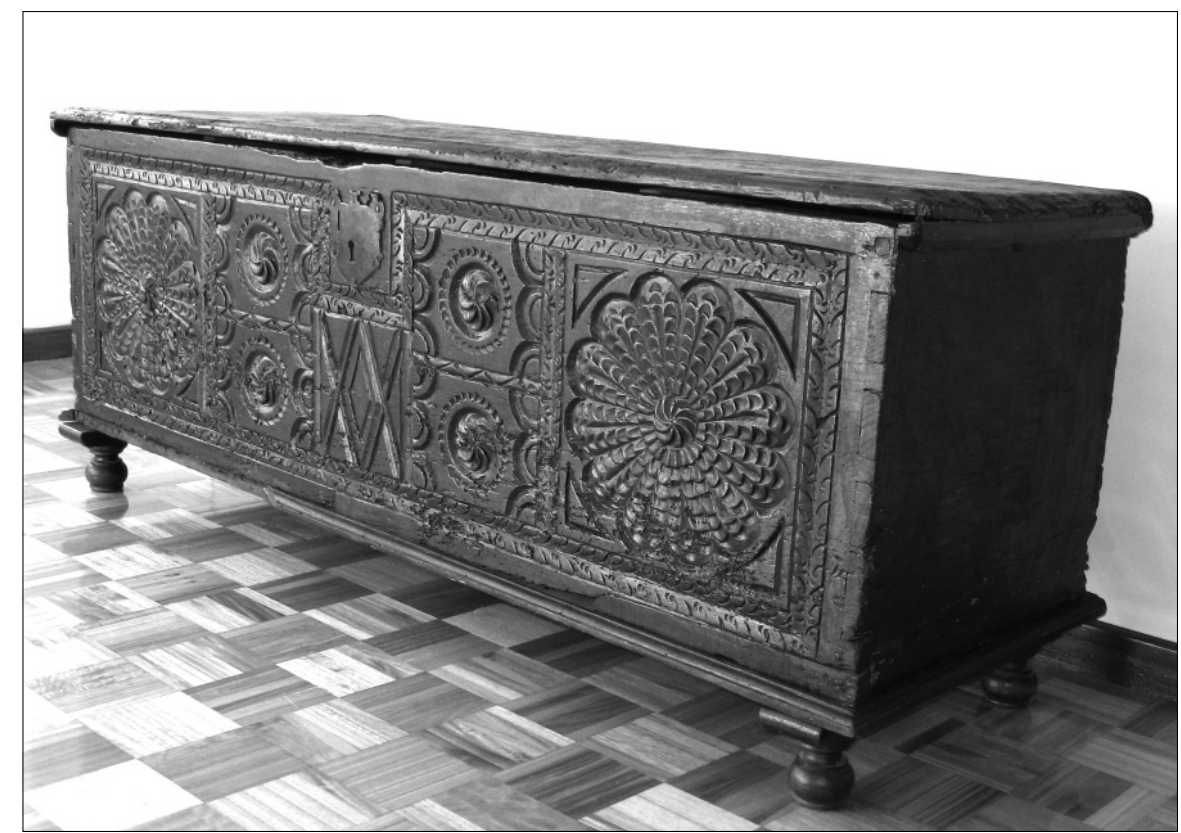

Figura 1. Tipo de arca más común entre las conservadas en Asturias. Colección particular, Oviedo. S. XVIII.

En su ya referido estudio sobre el mobiliario popular en los países románicos, Fritz Krüger dedica un amplio capítulo a las arcas, cofres y baúles, prestando particular atención justamente a aquellos muebles que por su

${ }^{12}$ Es frecuente encontrarse en la actualidad con piezas que presentan los costados tallados, casi siempre con motivos tomados del frente y adaptados al formato de los laterales, fruto de intervenciones realizadas a partir del primer tercio del siglo xx. 
calidad de traza y ejecución habían quedado en un claro segundo plano en los estudios sobre el mueble español que hemos venido citando. Reconoce que "entre los muebles que en las casas rurales de la Romania se han conservado hasta los tiempos recientes el arca de madera ocupa un lugar destacado" y señala una serie de funciones que encajan perfectamente con las que tiene esta pieza en Asturias: depósito de granos, sal y otras provisiones, siendo además el ropero básico hasta la tardía aparición del armario. Presta también servicio de asiento - llegando incluso a la forma más desarrollada del arca-banco-y puede ser utilizada incluso para dormir ${ }^{13}$.

Atendiendo a su estructura, distingue entre arcas excavadas en un tronco de un árbol; arcas cuyas paredes se encajan en cuatro sólidas pilastras que sirven a su vez de elementos de soporte y arcas cuyas distintas piezas se unen directamente formando una caja que a su vez pude presentarse elevada por medio de distintos elementos.

Resulta clara la existencia en Asturias de arcas excavadas en troncos, práctica por otra parte frecuente en la Europa central a partir del siglo XI. Excelentes ejemplos son el arca de tres llaves del antiguo Concejo de Leitariegos —fechado en el siglo XIV aunque con un modelo tipológico consolidado ya en la centuria anterior- y el arca de la Colegiata de Salas — de un tardío para la tipología siglo XVI-, ambos estudiados por Juaco López y Armando Graña (1986). Describen el primero, realizado sobre un tronco de castaño y reforzado con herrajes, como:

Arca construida con una sola pieza de madera, de grandes dimensiones, que ha sido ahuecada parcialmente en su tramo central para obtener el espacio útil a su función, pequeño en proporción al tamaño total de la pieza: poco más de la mitad de su longitud. De proporciones alargadas, sus costados han sido labrados para hacerlos planos y dar al mueble una sección cuadrangular, excepto en la cara superior, que conserva la superficie ligeramente convexa del tronco de árbol, tan sólo descortezado. Está trabajada toscamente, con hacha y azuela, por lo que las aristas resultan sinuosas y todo el conjunto ofrece un acabado irregular. El hueco practicable está cerrado por una tapa rectangular, formada por un grueso tablón que cubre algo más del espacio ahuecado y por tanto no ocupa más que una parte reducida de la cara superior del arca; dado que ésta es convexa se le hizo un rebaje en el que encaja la tapa.

La segunda de las piezas, aunque realizada sobre un tronco ahuecado a hacha y azuela presenta una factura diferente, con las superficies escuadradas y un espacio interior practicable mucho mayor.

\footnotetext{
${ }^{13}$ Aún es posible recoger testimonio orales de cómo el arca abierta servía de lecho, aprovechando la ropa guardada en él — generalmente ropa blanca de cama- como colchón.
} 
Por otra parte, los términos truébano o duerna remiten a este tipo de contenedores. El último de ellos ha llegado hasta fechas recientes reservado para distintas operaciones de la matanza del cerdo y como contenedor de la carne y huesos conservados en $\mathrm{sal}^{14}$.

Las arcas utilizadas en Asturias para la conservación de grano - y de judías tras su incorporación de tierra americana- mantienen las características estructurales definidas en el inicio de este apartado, aunque suelen carecer de decoración y presentar grandes formatos (Fig. 2). En la zona occidental de Asturias suelen identificarse como buchas ${ }^{15}$; tuñas cuando aparecen asociadas al hórreo o la panera hasta el punto de formar parte de la estructura de su cámara o colondra y perder en parte su condición mueble. Conviene tener presente que se han dado con frecuencia cambios de

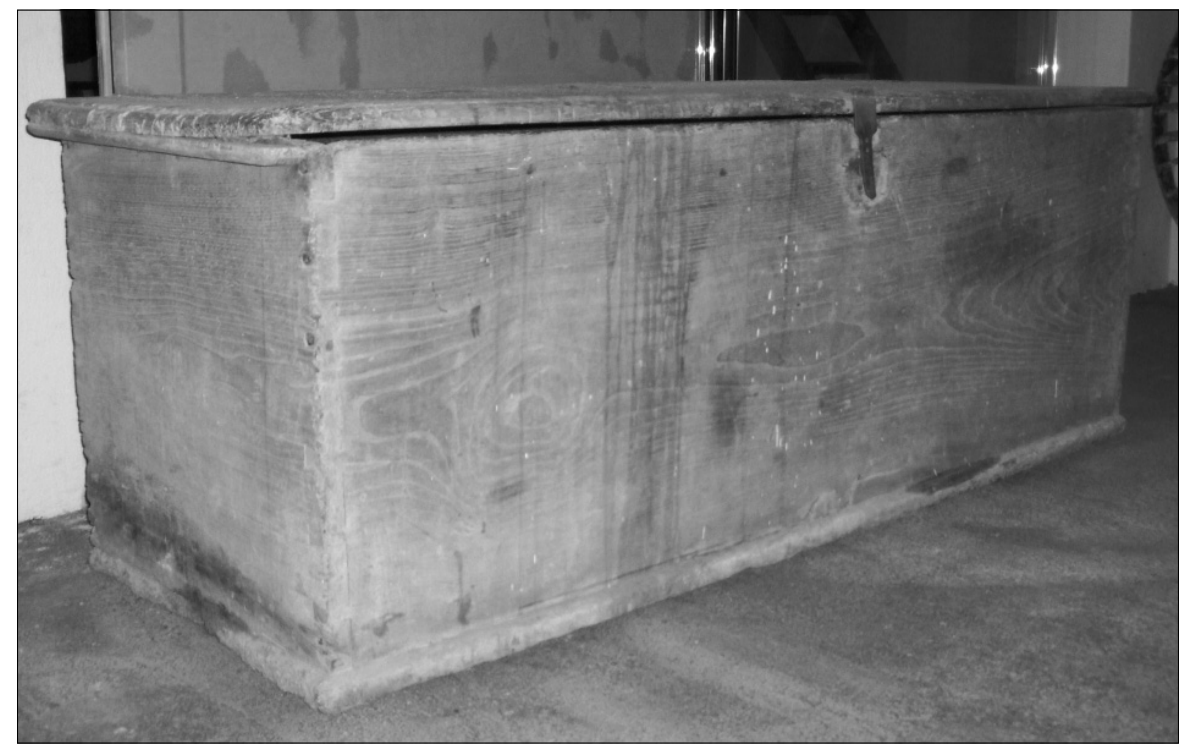

FiguRA 2. Tipo característico de arca para grano. Museo Etnográfico de Grado.

Asturias.

${ }^{14}$ Una pieza especialmente interesante por lo singular de su forma puede verse en la Casa Museo del Marqués de Sargadelos. Con este término se denomina también posible como masculino duerno o duernu - a la artesa en la que se maya la manzana previamente a su incorporación al llagar para pisar la sidra. La violencia del golpeo con mayos — potentes mazos de madera- exigía un recipiente especialmente sólido y resistente, haciendo particularmente apropiado el conseguido a partir del vaciado interno de un tronco.

${ }^{15}$ El término, sin embargo, no es exclusivo para esta función, pues lo hemos oído en la actualidad referido a muebles destinados a guardar ropas. 
uso, dedicando a arcas de grano algunas piezas en origen concebidas con otra función, pero que son reutilizadas al verse sustituidas en su función primitiva por piezas nuevas o de distinta tipología, aunque también dotando de usos ligados al ajuar doméstico arcas de gran sencillez pero con maderas de calidad que habían sido usadas en lugares no preeminentes de la casa como meros contenedores.

Respecto a los tipos señalados por Krüger, no se conocen en Asturias arcas con tapa a doble vertiente, que se tiene por particularmente primitivo y que se ha emparentado con el arca-sarcófago medieval. De arcas de pilastras conocemos algunos ejemplares aislados, lo que parece apuntar sin demasiadas dudas que se trata de piezas llegadas desde el entorno vasco, donde este sistema de armar fue el más común durante los siglos XVII y XVIII. Una pieza de estas características, de excelente calidad pero origen desconocido, se conserva en el Museo Etnográfico de Grado. Arcas de soportes laterales y de soportes frontales tampoco están representadas en Asturias.

\section{PReSENCIA DEL ARCA ENTRE El MOBILIARIO EN ÉPOCA PREINDUSTRIaL ${ }^{16}$}

Conforme se viene presentando en las revisiones de carácter general, presente ya en el Mundo Antiguo, el arca se convierte en el mueble más importante del Medievo. Evolucionando quizás a partir de las formas de sarcófagos griegos y romanos, alcanza en los siglos del románico su diseño más habitual en forma de caja alargada de tapa casi siempre plana y que frecuentemente recibe talla, se recubre con tela —arcas ensayaladas- o cuero (arcas encoradas) y se refuerza con clavos y herrajes ${ }^{17}$. Si bien el tesoro de la Catedral de Oviedo cuenta con arquetas de excelente factura -algunas, además, de particular valor simbólico, como el Arca Santa, la Caja de las Ágatas o la Arqueta de Santa Eulalia- no conocemos piezas de uso do-

\footnotetext{
${ }^{16}$ Tan sólo se pretende en este apartado trazar de forma muy sucinta los rasgos básicos de la evolución del uso del arca y sus formas en España, insertando algunos comentarios sobre la situación asturiana entre las principales convenciones sobre el uso y las formas de este mueble.

${ }^{17}$ La relación entre sarcófagos y arcas — tipológicamente muy próximos en lo formal aunque evidentemente distintos en su estructura y modo de armar por la propia disparidad de materiales - ofrece piezas sorprendentes. Simplemente a título de ejemplo, podría citarse la proximidad - en la técnica de talla y en los motivos decorativos- entre el sarcófago procedente del Monasterio de Sant Pere de Casserres (Osona) conservado en el Museu Episcopal de Vic (MEV 10623) y algunas piezas entre los siglos XVI y XIX del norte de España.
} 
méstico más comunes ni sus características ${ }^{18}$. La documentación escrita resulta además de escasa ayuda para el mundo del mueble en Asturias en esta época, pues las referencias son mínimas y extraordinariamente sucintas.

Otro tanto ocurre con las piezas de época gótica. Los estudios sobre mueble español insisten en señalar como comunes en este período las arcas con tracerías en los frentes, talladas o — en menor medida- caladas, precisando que se dejará notar de forma más intensa la influencia mudéjar y un desarrollo técnico que introduce armaduras y paneles. Hasta bien entrado el siglo XVI se utilizó mucho en Castilla la decoración de pergaminos (paneles que presentan como motivo tallado una suerte de pergamino sucesivamente plegado sobre sí mismo) mientras que en Valencia y Cataluña serán frecuentes las arcas doradas o policromadas. Una vez más, el grado de representación de piezas de estas características en Asturias es prácticamente nulo. A la luz de la documentación conservada de la baja Edad Media y muy especialmente de los testamentos, parece que el mobiliario, incluso entre las clases más acomodadas, era escaso y sin piezas particularmente apreciadas. Son excepcionales las citas entre los bienes dejados a alguna cama - aludiendo en ocasiones a la ropa de la misma y no a la estructura-, arquilla o arca con llave ${ }^{19}$. Queda constancia clara, no obstante, de la presencia del arca como mueble de seguridad (como "arcas de tres

${ }^{18}$ Según refiere César García de Castro (1999) el Arca Santa "consiste en un cajón de madera de roble, labrado a azuela [...] estando fijados los tableros y barrotes mediante pasadores cilíndricos de madera, espigas, muescas y rebajes, sin clavos metálicos". La madera está recubierta de chapa de plata nielada en la tapa y láminas de plata repujada claveteadas en las restantes caras. García de Castro reivindica además la concepción del arca precisamente como contenedor precioso y no como altar.

19 En el testamento de 9 de junio de 1289 de Pedro Díaz I de Nava (Torrente Fernández 1982: doc. 12) se mencionan unos lechos de ropa y una cama formada por un almadraque de flojel y otro de lana, tres faceruelos y un cabezal de flojel bordado en seda, una colcha cárdena, otra blanca y cuatro sábanas de tres paños cada una. Entre otros bienes suntuarios cita igualmente una caja con engastes y cadenas de plata. Referencia a la cama igualmente se realiza, aunque menos prolija, en el testamento de Arias Díaz de Noreña en 1324 (Torrente Fernández 1982: doc. 28bis) Por otra parte, el testamento de 1348 de Suer Alfonso II de Areces, que menciona "la ropa e preseas e estrongo de casa", cita concretamente la existencia de un arca con llave en su casa de Oviedo. Debemos estos datos a la generosidad de Jesús A. González Calle, autor de la tesis doctoral La nobleza en Asturias durante la baja Edad Media: génesis y evolución de linajes representativos (inédita). Como documento número 121 de su apéndice se recoge, de hecho, el último de los documentos citados. El propio González Calle señala que "Las noticias acerca de los objetos más preciados por los miembros de los linajes estudiados son ciertamente escasas, hasta el punto de que para algunos no contamos con una sola referencia". 
llaves" se conocen en general) en el que se custodiaban sellos, documentos, alhajas y caudales de todo tipo de instituciones y asociaciones; caso de concejos y ayuntamientos ${ }^{20}$.

A finales del siglo Xv, la denuncia realizada por Martín Alonso de Oviedo en noviembre de 1491 de un robo del que acusa a Juan de Argüelles nos ofrece referencia exacta del uso de un arca y de los elementos que podía contener $^{21}$. Declara exactamente que se le abrió un arca:

en que tenía dineros e plata, e que le llevó y furtó d'ella una taça grande de plata e una copa de plata e una çinta de plata, e çiertas cucharas, e ocho sortijas de oro con sus piedras, e ciertos ducados e castellanos, que diz que podía todo valer más de treynta mille maravedís

A pesar de la incorporación de algunos nuevos tipos de muebles y de la redefinición de los interiores, el arcón continúa siendo un mueble omnipresente en los siglos del Renacimiento ${ }^{22}$. En el caso de las piezas más lujosas - destinadas generalmente a guardar ropa y otras alhajas- los frentes reciben ahora decoración ajustada a los nuevos gustos y estilos ${ }^{23}$, manteniéndose además una corriente popular que tiene en un repertorio de sencillos motivos geométricos que resuelve con una talla a bisel $-\mathrm{y}$ que

${ }^{20}$ Recogen López y Graña (1986: 26) que en las cartas de población que otorga el Obispo de Oviedo a los vecinos de Castropol (1300) Langreo (1338) o Las Regueras (1421) se incluye siempre la condición de que "el sello del dicho concello que estia en vna arca en casa hun omne bono morador en la dicha pobla, e que a la tal arca que la pongan dos cerraduras e en cada cerradura la sua llave". Parece que hasta el siglo XIX estuvo en uso el arca de tres llaves del ayuntamiento de Salas y aún en 1798 la Junta General del Principado encarga a Juan Pruneda Cañal, por entonces ya "Maestro de Evanista Ensamblador de Nogal", la ejecución de un arca de tres llaves para función de archivo (Friera 2007: 68).

${ }^{21}$ Archivo General de Simancas. Registro General del Sello, 1491, noviembre, folio 43. Tenemos conocimiento de este documento por Jesús A. González Calle, que nos ha facilitado también su transcripción. Quede constancia de nuestra gratitud.

22 Iglesias y conventos comienzan a desarrollar muebles específicos más aptos para guardar sus enseres y ornamentos, generalizándose armarios y cajoneras, mientras que el arca permanece como mueble de uso en los interiores domésticos (Aguiló 1993: 117) De todos modos, es evidente que muchas arcas permanecerán en uso. De las ejecutadas para la catedral de Oviedo han llegado a nosotros cajoneras de las contratadas en 1668 y de las ejecutadas en varias tandas en la segunda mitad del XVIII, sin embargo, las alhajas de la Capilla del Rey Casto — una de las más importantes del templo— se guardaban aún en el siglo XVIII en arcas y cajas de madera.

${ }^{23}$ Sin variaciones sustanciales en la estructura, se incorpora talla de bustos y grutescos y se mantiene aunque desplazado el diseño de los pergaminos. Según refiere Aguiló (1987: 123) "el tipo que más abundantemente se da es el de un solo panel, que ocupa todo el frente, tallado con escudos entre tallos con animales y figuras fantásticas, o con escenas". 
comparte toda la Europa agraria - nómina eficaz para responder a una demanda de decoración que lleva implícitos frecuentemente también otros significados y finalidades (Fig. 3). Dado el enfoque de este trabajo, resulta especialmente interesante la apreciación de Mạ . Paz Aguiló (1987: 124) respecto a que "en el norte comienzan a aparecer los primeros inventarios que permiten atribuir al siglo XVI tipos de decoraciones que aparecen en el mobiliario popular de los siglos XVII y XVIII".

Es posible rastrear en Asturias a través de los documentos una presencia creciente del arca entre las piezas de mobiliario doméstico, contándose además entre las más apreciadas. Así, por ejemplo, en el inventario de bienes realizado por María Pérez, viuda del armador de pesca candasín Bastián García de Folguera, en 11 de enero de 1611 - y recurrimos a esta cita por cuanto puede ofrecer una imagen de la presencia de este tipo de mueble

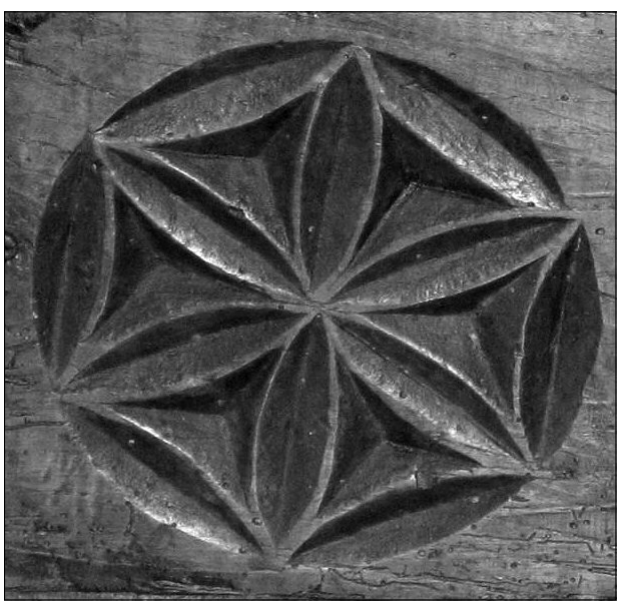

Figura 3. Hexapétala inscrita en un círculo. Uno de los motivos más comunes en el arte popular de la Europa agraria, particularmente la atlántica. entre una clase acomodada pero no noble ni ligada al poder- se citan dos arcas grandes con sus cerraduras, otra más pequeña también con cerradura y dos arcas viejas, una en el hórreo y otra en la $\mathrm{casa}^{24}$.

Particular atención han despertado entre el mobiliario español de este período las arcas catalanas, que penetran a través de Venecia en los últimos compases del gótico para experimentar una compleja y rica evolución y que con frecuencia incorporan decoración pintada ${ }^{25}$.

La importancia adquirida por la madera en las artes españolas de los siglos del Barroco afectó sin duda al mundo del mueble. La carpintería y la ebanistería, unidos vectorialmente a talleres de escultura, experimenta un notable avance y el mueble se hace partícipe de todos los elementos que configuran el nuevo estilo. El arca se mantiene como una pieza omnipresente en el amueblamiento, si bien la generalización a lo largo del siglo XVI de muebles como

${ }^{24}$ Tenemos noticia de este documento a partir de un artículo publicado por la profesora M. ${ }^{\underline{a}}$ Josefa Sanz Fuentes (2008).

${ }^{25}$ Ver Aguiló (1974: 249-271) y, para una revisión más reciente. Piera y Mestres (1999). 
el escritorio o algunos modelos de armario hará que pierdan preeminencia en entornos cultos o más receptivos a las modas. Aguiló Alonso (1993: 85) realiza una interesante apreciación al distinguir entre las arcas de excelente factura y que solían tener una ubicación permanente y aquellas destinadas a contener grano o enseres domésticos. De estas últimas dice que "aún las más decoradas correspondientes a las zonas del Norte, pertenecen al arte popular", añadiendo en nota al pie que a pesar de existir algunos ejemplares del siglo XVII, los tipos quedan fijados a partir del siglo XVIII. Según esta misma investigadora (Aguiló 1987: 191), es de las arcas de novia — siempre de esmerada factura- de donde arrancan los tipos regionales y populares que habrán de repetirse con escasa variación a lo largo de los siglos XVII y XVIII.

A pesar de que en determinados ambientes el armario, según se ha apuntado ya, va adquiriendo cada vez más importancia, persisten cofres y arcas, que sólo entre las clases más elevadas encuentra competencia en la cómoda. Insiste Feduchi (1986: 92) para este período en que "los muebles más originales e interesantes son los que pertenecen al grupo popular", realizados por "artistas castellanos, educados y acostumbrados a nuestro Renacimiento, recio y austero, y a sus características; en él entra perezosamente el arte nuevo y el rococó francés, y se producen obras interesantes de tiempos pasados (arcón, bargueño, frailero) con un sello netamente regional". A partir del siglo Xvi la doctora Aguiló Alonso (1987: 192-193) deja perfectamente perfilado el panorama en su evolución general.

En el catálogo de la exposición Mueble Español. Estrado y dormitorio profundiza ya la investigadora en las peculiaridades regionales (Aguiló 1990) esbozando la evolución del arca catalana — tema al que dedicara uno de sus primeros estudios, ya citado- y apuntando el de otras regiones. Así, por ejemplo, refiere como comunes en Castilla, especialmente en la zona de Valladolid, arcas de castaño o nogal de gran sencillez que incorporan hierros calados en las esquinas. Cita agrupadas las arcas populares de las regiones cantábricas, singularizándolas por la decoración tallada o incisa de un repertorio de motivos entre los que se cuentan abanicos, discos radiales y jarrones con flores, dispuestos frecuentemente de forma simétrica en torno a una cruz, un emblema o una inscripción eucarística que funciona como eje. Señala igualmente que es común la presencia de fechas e inscripciones de autoría y precisa respecto a la evolución estilística de estos motivos que "las composiciones más geometrizadas de la primera mitad del siglo dejan paso, en contacto con el barroco, a líneas más movidas con tallos ondulantes, flores, pájaros y corazones". Reconoce dos modelos un tanto peculiares; un tipo de arca con decoración de paneles compartimentados con columnas torneadas o anilladas con decoración vegetal y faldón con arquería 
calada de balaustres y por otro lados las denominadas kutxas vascas, entre las que se encuentran las denominadas kutxas de caballos estudiadas por Manso de Zúñiga (1962).

Aunque no cita específicamente el caso asturiano, como tendremos ocasión de repasar a continuación, el marco general expuesto es referencia válida para interpretar las arcas de Asturias y su decoración. Es posible rastrear a través de la abundante documentación conservada de los siglos XVII y XVIII - especialmente en testamentos, inventarios y capitulaciones matrimonialesla presencia del arca en los espacios de uso de distintas clases sociales ${ }^{26}$ — evidentemente, de aquellas con capacidad para dejar rastro escrito-, pero muy rara vez se anotan datos respecto a la decoración o la calidad de las piezas. Su ubicación en alguna de las dependencias de la vivienda, su condición de vieja o retirada, la materia con la que está confeccionada en el mejor de los casos, y casi siempre la cantidad y estado de sus cerraduras constituyen los datos referidos más comúnmente.

La incorporación del armario al mobiliario común de las casas asturianas no debió producirse, y entre las clases más acomodadas, hasta mediado el siglo XVIII. Si en el inventario de alhajas que deja el Marqués de Valdecarzana en su casa de Grado, fechado en $1719^{27}$, no se cita aún ningún armario — frente a veinte arcas en uso, más cajas y cofres-, no hemos encontrado en el espigueo llevado a cabo hasta el momento entre los inventarios del Archivo Histórico Provincial cita alguna a armario entre campesinos propietarios, artesanos o comerciantes, que siguen teniendo en el arca su principal mueble de guardar, ni siquiera en las últimas décadas del $\operatorname{siglo}^{28}$.

Es evidente que por más que en el mobiliario español del siglo XIX y del xx el arca se convierta en una pieza residual sigue muy presente entre las clases populares asturianas. Heredadas, recibidas en ocasiones por los colonos procedentes de las casas señoriales de los propietarios de sus tie-

${ }^{26}$ López y Graña (1988b: 333, 334) ofrecen un ejemplo de las diferencias de mobiliario entre colonos y campesinos propietarios a partir de tres inventarios del primer tercio del siglo XVIII en el concejo de Colunga protocolizados por el escribano Benito de Arguero.

27 Transcrito como apéndice documental en De la Madrid (2005).

${ }^{28}$ A modo de ejemplo, hasta siete arcas — dos al menos para ropas y efectos personales - tenía el acomodado labrador de Ventanielles (Oviedo) Pedro Álvarez Valdés según el inventario realizado el 27 de enero de 1790; tres arcas "buenas" —una de ellas "chica"- y dos cofres en su casa, y dos arcas más en la tienda el comerciante de tejidos Juan Rodríguez Ridoces, también asentado en Oviedo y cuyos bienes se inventarían en el mismo año. (Ante Antonio Fernández Solís, Archivo Histórico de Asturias. Sección Protocolos Notariales del Distrito de Oviedo. Caja 8359, ff. 25 r y sigs. y 44 r y sigs.). 
rras, las arcas continuaron siendo una pieza de prestigio en el mundo rural y en muchos casos prácticamente el único mueble contenedor de envergadura hasta bien entrado el siglo xx. Se experimentarán avanzada esta centuria distintos fenómenos; por una parte muchas de estas piezas modificarán su uso y su ubicación - dejando su lugar de privilegio en salas y alcobas para ocupar zaguanes, pasillos, y en mayor medida hórreos y trasteros-, al tiempo que serán objeto de interés por parte de algunos miembros de la burguesía local, que las adquiere con cierto sentido coleccionista y que lleva hoy a encontrarse en chalets, palacetes y casonas de los ensanches burgueses de ciudades y villas asturianas con agrupaciones notables de piezas.

\section{DECORACIÓN DE ARCAS EN ASTURIAS. MOTIVOS Y EVOLUCIÓN}

Es claro que en buena parte de Asturias estuvieron decoradas las arcas destinadas a contener ropa de ajuar u otros elementos preciados y que formaron parte del mobiliario principal de las dependencias más nobles de la casa. No creemos que haya existido una diferenciación tipológica o estructural entre las piezas usadas por las distintas clases sociales - aquellas que tenían algo que guardar-, aunque resulta fácil pensar que conforme se ascienda en su pirámide aumentaría el número de ejemplares por vivienda y su calidad; calidad que residiría fundamentalmente en la de la madera - a los más pudientes quedarían reservadas las arcas de nogal- y en la decoración. Un campesino avezado pudo, sin duda, labrar con pericia alguno de sus muebles, bien desarrollando su propia creatividad en el sentido más pleno o bien copiando o reinterpretando algún modelo que hubiese pasado por su retina. En el extremo opuesto, el estado noble acudiría a ebanistas y ensambladores de prestigio, con talleres abiertos en las principales ciudades y villas de la región, sin olvidar que tendrían capacidad como para adquirir piezas de enclaves foráneos, como demuestra la documentación que hicieron ${ }^{29}$. En medio quedarían abiertas muchas posibilidades que cubrirían desde campesinos con conocimientos de carpintería y que, como señala el Catastro de Ensenada, trabajan la mitad del año en pequeños talleres locales que componen y decoran hórreos y paneras, realizan carpintería de obra o armaduras y cierres varios de madera, según la demanda ${ }^{30}$.

${ }^{29}$ Con frecuencia la zona o localidad de origen se incorporó al nombre de la pieza, citándose así en los inventarios y recuentos. Es frecuente, por ejemplo, la alusión a "escritorios de Salamanca". No hemos localizado, hasta el momento, referencia alguna similar para las arcas.

${ }^{30}$ Poco se sabe sobre el oficio de la carpintería y la ebanistería en Asturias en el Antiguo Régimen. El grado de implicación de los carpinteros de ribera en obras de otra 
La propia movilidad del mueble, sobre todo cuando la pieza conservada es el único elemento susceptible de analizar, sin apoyo documental, dificulta enormemente su estudio y la posibilidad de establecer una secuencia evolutiva en las formas que pueda perfilar una cronología o contribuir a la adscripción de autoría. Frente a la relativa abundancia de cartelas e inscripciones asociadas a la labra de hórreos y paneras, decisiva para trazar su historia $^{31}$, y que consideramos un referente de enorme utilidad para abordar el análisis del mueble popular, éstas son en el mueble prácticamente inexistentes. De hecho, tan sólo conocemos un arca fechada en la parroquia de Logrezana (Carreño), y de fecha tan tardía como 1879. La mayor parte de las piezas conocidas, además, se corresponden a lo que se viene denominando "corriente popular", por lo que no siempre mayor tosquedad formal implica mayor antigüedad. Esto es, encontramos "barajadas" piezas que en su día dieron satisfacción a la demanda de clases sociales distintas, que proceden de épocas distintas y cuya localización actual sólo excepcionalmente se corresponde con la original.

Concebida como mueble arrimadero, el arca presenta la trasera siempre labrada de forma tosca - frecuentemente son reconocibles las marcas de la azuela en un regruesado que ni siquiera se detiene en el uso de garlopa o cepillos- volcando la decoración al frente principal, de proporciones alargadas. Regla básica en la composición es siempre la de la simetría. La disposición centrada de la cerradura traza un eje en torno al cual se disponen los elementos, si bien es cierto que no es raro que en el detalle éstos presenten algunas variaciones mínimas de forma o diseño que rompen lo estricto del esquema.

Conocemos piezas que despliegan en sus frentes desarrollos geométricos muy próximos, si no idénticos, a algunos motivos frecuentes en la decoración arquitectónica del siglo XVII consistentes en la alternancia de círculos y cuadrados encadenados, así como algunos cuajados de rectángulos moldurados a modo de cuarterones o con cierto recuerdo de la imagen interior de papeleras y escritorios, pero son casos excepcionales. Es común entre las arcas conservadas en Asturias que la pieza que funcione como fron-

índole e incluso en la confección de mobiliario, la repercusión de los talleres catedralicios sobre el amueblamiento de los palacios ovetenses, la envergadura de pequeños talleres locales, sus modelos e influencias, son entre otros muchos aspectos, cuestiones aún pendientes de estudio.

${ }^{31}$ Se conoce un pequeño número de fechas de principios del siglo XVI que ha permitido atribuir a esta cronología por tipología, detalles estructurales e identidad estilística centenares de hórreos; hay mayor número de fechas del xvil y el nombre ya de varios maestros carpinteros, aumentando la cifra de fechas y nombres para los siglos XVIII y XIX. Remitimos a la bibliografía reseñada sobre hórreos y paneras de Asturias. 
tal reciba una moldura perimetral retirada unos centímetros de los bordes y quebrada en el espacio que albergará la cerradura, incluso cuando ésta no haya sido instalada nunca. Sencillos boceles, zing-zags incisos, cenefas de barras, triángulos biselados o en espina de pez, así como orlas conseguidas jugando con golpes de gubia vaciados con mayor o menor realce o sólo marcados, se encuentran entre los motivos más frecuentes ${ }^{32}$. Ese ligero estrangulamiento central será el que marque tres áreas básicas en la organización de la decoración: un espacio central coincidente con el eje de simetría, y por tanto de algún modo privilegiado, y dos campos iguales a izquierda y derecha. Cada uno de ellos pueden verse ocupados por motivos diversos de forma aislada o compartimentarse al tiempo con nuevas molduras o enmarques. Esos marcos tienden a estructurar el espacio en plafones cuadrangulares, variando el número en función del formato del frontal.

En dos grupos se podrían organizar los motivos empleados; por un lado está el fecundo repertorio de motivos circulares, comunes entre los pueblos agrarios de la Europa Atlántica (rosetas — de forma especialmente abundante la hexapétala-, radiales rectos y curvos, tetrasqueles, comas), y por otro estilizaciones vegetales (florones, rosetas, hojas), en muchos casos sometidas a enmarques geométricos, que pueden adquirir sabor barroco (Fig. 4). Es difícil saber en qué medida los primeros se han convertido en meros motivos decorativos de fácil trazado con el conocimiento de reglas sencillas de geometría y sin más herramientas que una escuadra y un compás o perviven en ellos viejos significados que asocian aún esos motivos circulares con el Sol, astro del bien y de la vida, y que mantienen por tanto un sentido protector ${ }^{33}$. Los se-

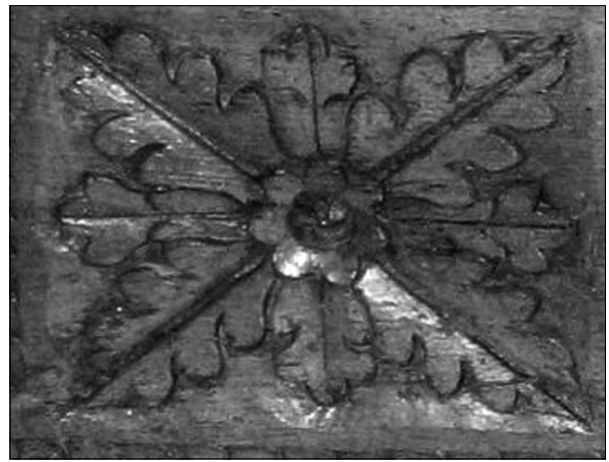

Figura 4. Florón de hojas de roble del frente de un arca. Colección particular, Heres, Gozón. S. XVIII.

\footnotetext{
${ }^{32}$ El gusto por la variedad y la lectura de la multiplicidad de motivos como riqueza hará, no obstante que sean frecuentes las excepciones. Así, es posible encontrar arcas que carecen de este enmarque - caso de algunas de las que analizaremos en el apartado siguiente-, arcas que presentan cenefa tan sólo en la parte superior e inferior del frente; cenefas que se interrumpen en torno al plafón o escudo de la llave, sin trazar su perfil, o arcas que recurren a motivos distintos para trazar cada uno de los segmentos de la cenefa.

33 Para una revisión general de los principales significados de estos motivos, su pervivencia y evolución en el tiempo, con abundancia de ilustraciones (Álvarez 2002).
} 
gundos, dentro de esquemas muy próximos, mostrarán un sinfín de posibilidades interpretativas, de combinaciones y ejecuciones.

Motivos zoomorfos y antropomorfos son claramente excepcionales. Aves afrontadas aparecen en algunas piezas y aún más raramente figuración humana. Aunque se hayan apuntado algunas ideas singulares en clave local para explicar la existencia de las primeras, sobre todo cuando van asociadas a la cruz en contextos populares (Hevia 2004: 16, 17, 33), hay que entenderlas entre las más habituales de las de composición heráldica desde antiguo (del mundo Antiguo a tejidos orientales pasando por todas las representaciones plásticas del mundo medieval y especialmente la miniatura). Utilizadas en mosaicos, relieves o tejidos, se encuentran también entre los motivos presentes en el mueble culto. Respecto a la figuración humana, resultan interesantes varias piezas localizadas en el concejo de Gozón en las que aparece presidiendo la composición una figura femenina de traza absolutamente ingenua pero que creemos explicita el carácter nupcial que comparten muchas de las arcas (Díaz 2005: 136, 137).

Si bien en las arcas de menor alzada el espacio central bajo la llave suele estar ocupado por un motivo decorativo, es frecuente que ahí se trace un diseño de claro carácter protector. El más común será sin duda la cruz, ajustada a distintos modelos ${ }^{34}$, aunque aparece también la custodia ${ }^{35}$ —más o menos estilizada en su traza- o cartelas con conocidos anagramas piadosos como IHS o la M y la A enlazadas de carácter mariano ${ }^{36}$ (Fig. 5). Cabría agrupar un buen número de piezas que despliegan partiendo de la cruz sinuosas estilizaciones vegetales rematadas en abanicos que traducen de forma más o menos directa inflorescencias. Este desarrollo puede llegar a ocupar el tercio central del arca, e incluso más, acompañándose en los extremos por plafones cuadrados centrados siempre por motivos circulares (estilizaciones vegetales en unos casos, radiales rectos en otros). El esque-

${ }^{34}$ Abundan las cruces latinas sobre monte triangular, incisas o cuajando el campo de celdillas a bisel para generar plásticos claroscuros. Llevan en ocasiones comas o vírgulas —estilización máxima de aves, quizá - asociadas, así como motivos geometrizados de sentido astral. Más raras son las de Malta, aunque se conocen algunos ejemplares.

${ }^{35}$ La custodia enlaza en lo formal, sobre todo en los diseños más esquemáticos, con todos esos motivos circulares que tiene asimilados la memoria popular. Ni siquiera hay ruptura en el significado cultual al presentar a Jesús Sacramentado como "nuevo sol" y convertir la pieza litúrgica que lo expone en elemento protector que trae asociadas, además, resonancias de fiesta y abundancia. Ver Díaz Quirós (2003).

36 Conocemos un arca en la parroquia de San Jorge de Heres (Gozón) con una inscripción mariana a tinta en la parte interior de la tapa. Se trata del inicio de una conocida oración, "María madre de gracia madre de misericordia...", que en la parte no explicitada adquiere, una vez más, un sentido protector. 


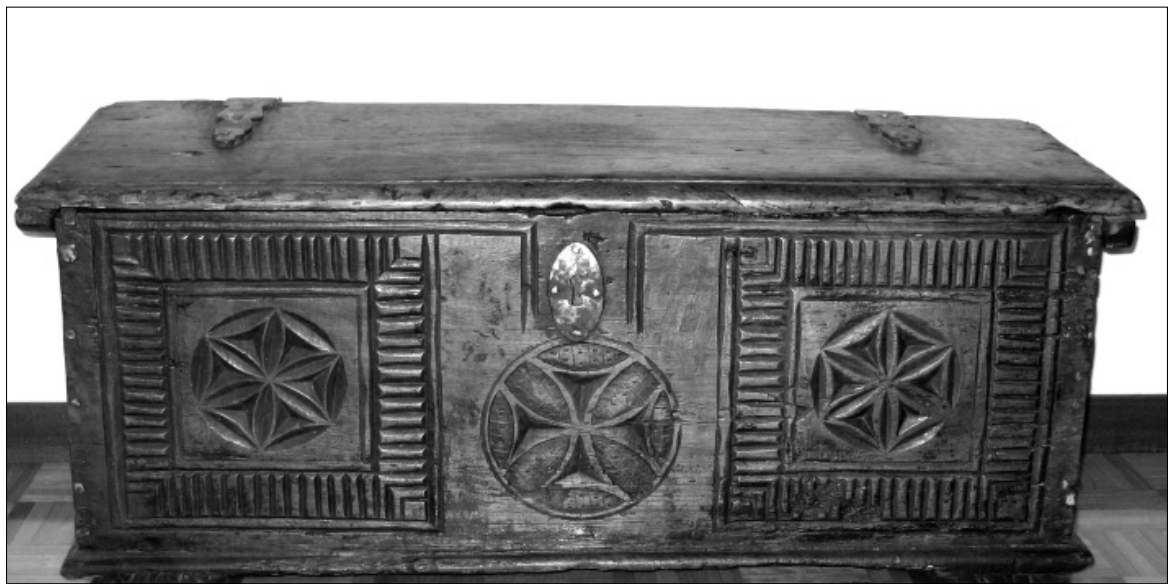

Figura 5. Arca con cruz de Malta. Colección particular, Oviedo.

ma parece iniciarse a finales del XVII, desarrollándose en el XVIII para llegar a finales de la centuria con trazas de gran elegancia en la que los tallos vegetales se han convertido en tornapuntas en "C" y en "S" bien perfiladas que funcionan como pie de sencillas cruces (Fig. 6).

El arcaísmo de la factura — con tipos que aún no responden al formato rectangular del frente tan común en adelante-, la disposición de motivos con inusitada libertad y la importancia concedida entre estos a motivos cir-

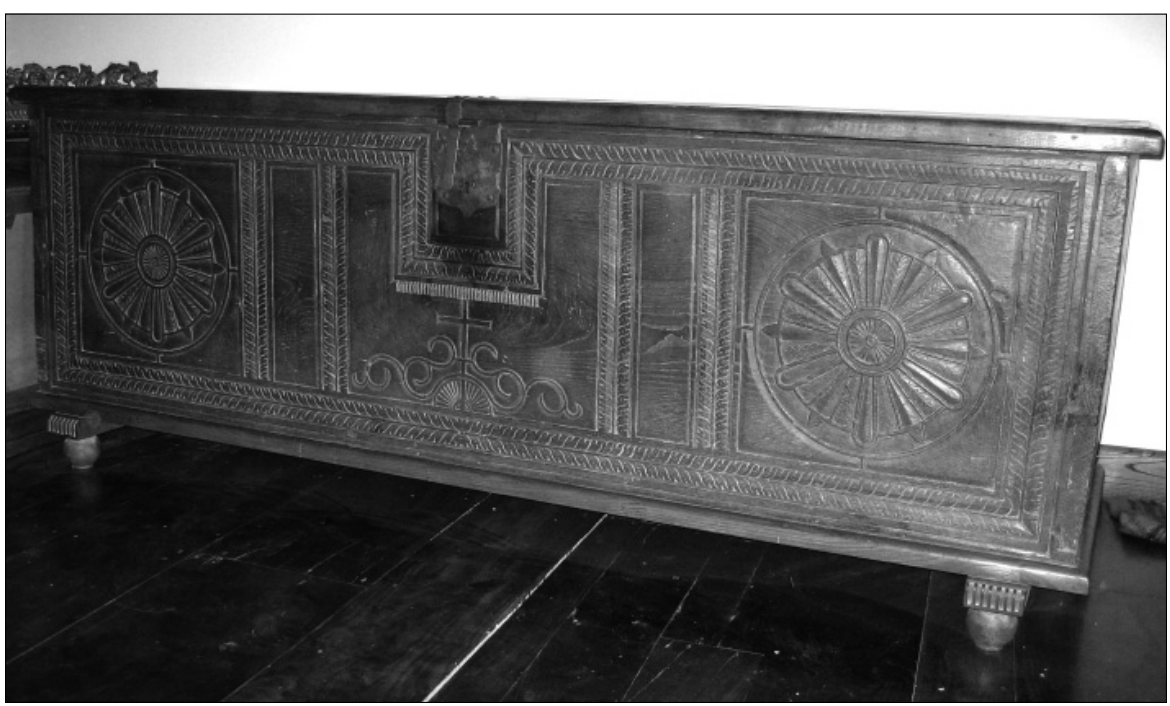

Figura 6. Arca. Colección particular, Luanco, Gozón. S. XVIII. 
culares, usando además de una técnica de talla a bisel, próxima a la que conocemos para hórreos fechados en el siglo XVI, nos lleva a pensar en esta centuria para algunas piezas, si bien muy escasas en número. Como señalara la doctora Aguiló, según se ha referido, parece probable que hayan sido algunos modelos de calidad del siglo XVII los que en mayor medida dejasen su impronta en la producción local, fijando modelos para el siglo siguiente. Entre estas piezas se encontrarían algunas realizadas en nogal que componen frentes de gran elegancia utilizando sencillos rebajes y motivos vegetales de delicada factura, trazados sobre esquemas geométricos igualmente sencillos, sin la pretendida exuberancia barroca ni el gusto por el abigarramiento frecuente más adelante ${ }^{37}$.

Como demuestran nuevamente los trabajos de talla realizados sobre hórreos y paneras o sobre la carpintería de obra de edificios religiosos, casonas y palacios, en la segunda mitad del siglo XVIII — superadas las graves crisis de las dos primeras décadas del siglo- se desarrollaron, sobre todo en el área central de Asturias, numerosos talleres locales de trabajos en madera que mantendrán su actividad, con obras de gran vistosidad y notable calidad técnica, hasta finalizar la centuria. Sin descartar que artesanos formados en talleres dedicados a la imaginería religiosa y la talla de retablos se viesen abocados a la ebanistería (López y Graña 1988: 337) lo cierto es que no apreciamos una auténtica trasposición de modelos o motivos. De igual modo, por más que la decoración de hórreos y paneras resulte, como hemos defendido, un referente desde distintos ángulos para abordar el estudio de la aplicada sobre muebles, salvo casos puntuales — de gran interés, por otra parte- la repetición de diseños en uno y otro ámbito por la misma mano resulta menos frecuente de lo que pudiera aventurarse ${ }^{38}$. Uno de estos casos sería el del taller gozoniego de los Fernández Corugedo, activo en las décadas centrales del siglo XVIII y cuya obra sobre graneros conocemos bien por haber dejado significativas cartelas con fecha y firma (Díaz 2005: 135-137, nota 19). Si bien ninguno de los muebles conocidos y que suponemos de su mano presenta firma, la singularidad de algunos de sus motivos tallados — particularmente un campo reticulado cuajado de palmetas que parecen arrancar en su diseño de una flor de lis y dobles ces al bies-

${ }^{37}$ Hemos localizado en el área central de Asturias un buen número de piezas que, en conjunto o en algunos detalles significativos están muy próximas a un ejemplar reproducido por Krüger (1963: foto 35) e identificado como obra leonesa del XVII.

38 Para profundizar en las características de la talla aplicada a hórreos y paneras en el siglo XVIII ver Díaz (2001), González (2002) o Díaz (2006), con cita exhaustiva en este último caso de la bibliografía sobre el tema hasta la fecha. Hemos dado a imprenta recientemente un trabajo sobre maestros y talleres del área central de Asturias. 
y la técnica con que se resuelven facultan para una atribución con pocas dudas $^{39}$ (Fig. 7).

Según se ha apuntado, florones vegetales, hojas - especial predicamento tendrán las del roble, por conocidas y por su alabeado perfil- y rosetas de carácter vegetal se convierten en motivos predominantes en el siglo XVIII. Los viejos diseños circulares, sobre todo la hexapétala, no desaparecen, pero reciben un tratamiento distinto tanto en composición como en ejecución. El horror vacui se hace evidente en la mayoría de los trabajos, cuajando los fondos de punteados, rasgados o marcas de gubia cuando la talla de mayor plasticidad no recubre por completo la superficie decorada.

El siglo XIX traerá a las arcas un aire nuevo. Los jarrones con flores, presentes ya en obras de taracea anteriores, pero trazados ahora de una forma absolutamente esquemática, se convierten en un motivo frecuente. A su vez, la nómina de motivos que se presentara organizada en dos grupos se mantiene, si bien resuelta con mucha menor coherencia y calidad técni-

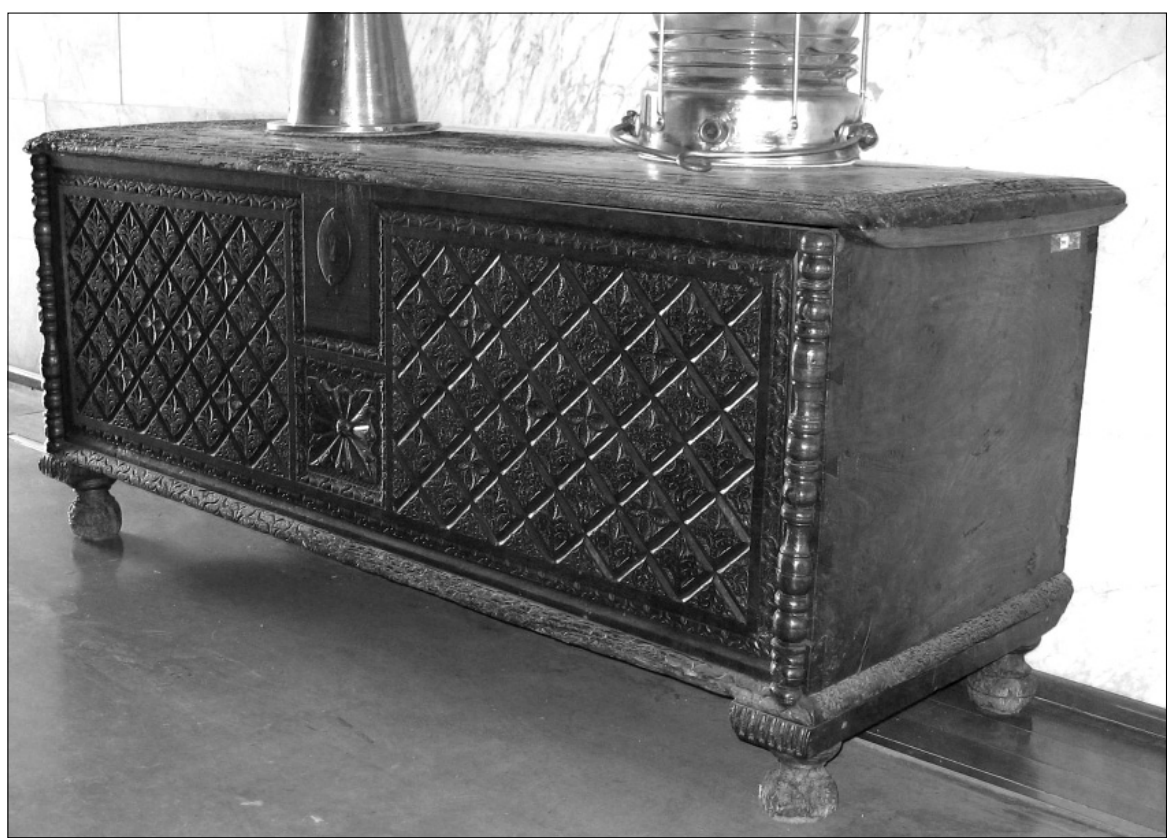

Figura 7. Arca del taller de los Fernández Corugedo. Museo Marítimo de Asturias, Luanco. Mediados del siglo XVIII.

39 Además de las piezas estudiadas en el artículo citado hemos localizado recientemente varias arcas más y dos excelentes bancos con respaldo recto sobre balaustre torneado, tallado precisamente con los motivos característicos del taller. 
ca. Como norma, y sin perjuicio de piezas de talla excelente, evidentemente, los motivos vegetales se simplifican, recurriendo al gallonado rehundido a modo de pétalos o a la mera incisión de trazos efectistas o formas caprichosas.

En las décadas finales del XIX y las primeras del XX, en gran medida como consecuencia de la fuerte emigración, se popularizará el uso de cofres y baúles de viaje, generalmente realizados en pino, forrados al interior con telas o más comúnmente papeles estampados y reforzados en el exterior por costillas de madera claveteada, herrajes y paneles de latón que protegen y decoran al tiempo. Muchas de estas piezas terminaron por servir como muebles habituales en cuartos y alcobas. Fruto también de las experiencias transatlánticas será la recepción de algunas arcas de gran sencillez pero ricas maderas exóticas ${ }^{40}$.

A un paulatino descenso de la ejecución de arcas, que ya no estaban entre las piezas demandadas por las clases más pujantes y acomodadas de la sociedad asturiana conforme avanzaba el siglo XIX, parece haber seguido un repunte en el primer tercio del siglo xx que pervivirá en los años 40. Parece probable la fusión de una tradición no extinguida con una nueva demanda en la órbita del regionalismo y que convive con la explosión del estilo remordimiento o padecimiento español. Esa incoherencia en el uso de motivos a la que antes aludíamos se verá entonces acrecentada, utilizando motivos diversos de entre los frecuentes en la tradición anterior combinados con formas nuevas; diseños tomados de repertorios publicados e industrializados o fruto de la inventiva de ebanistas y artesanos. Así, existen arcas con cabezas de guerreros, escenas del Quijote, reinterpretaciones de cenefas, roleos o candelieri, hojas de acanto y un amplio etcétera en piezas que quedan reducidas prácticamente a una función decorativa y que ven menguado considerablemente su formato. La pretensión de antigüedad llevará a recurrir a estereotipos, aplicando, por ejemplo, hierros, bisagras y escudos de cerraduras muy trabajados montados sobre fieltros de color al modo de lo conocido — y cada vez más publicado- de otras áreas geográficas. El reaprovechamientos de piezas antiguas o la copia literal de algunos motivos no hará fácil siempre reconocer la cronología de algunas de estas obras.

\footnotetext{
${ }^{40}$ Caso de una de madera de cedro llegada a Gurullés, Reconco.
} 


\section{ARCAS EN EL CONCEJO DE GRADO}

En el contexto de un trabajo de campo orientado a la localización de piezas susceptibles de ser incorporadas a la colección de su Museo Etnográfico tuvimos ocasión de localizar varias arcas, un buen número de ellas con decoración, en el concejo asturiano de Grado ${ }^{41}$. Presentamos una selección de piezas que por distintas razones consideramos de interés, con la intención de contribuir a la generación de un corpus de mobiliario que permita un día generalizaciones fundadas.

El propio Museo Etnográfico de Grado custodia un total de seis arcas; cinco de las cuales están expuestas de forma permanente, mientras que una más, muy deteriorada, se encuentra en los almacenes. De entre las expuestas, una de ellas se ubica en la sección dedicada a los trabajos de carpintería; arca de castaño de gran formato $(70 \times 193 \times 64 \mathrm{~cm})$, de tablas enterizas ensambladas con cola de milano para armar la caja, clavado el fondo y sin decoración, ha sido reaprovechada en época indeterminada para recoger ordenadas diferentes herramientas de carpintero, habiéndosele clavado en su interior distintas piezas de madera especialmente orientadas a este fin.

De las dos arquillas pequeñas (de menos de $40 \mathrm{~cm}$ de alto) existentes, ambas muy intervenidas, resulta original la decoración de una de ellas, que recurre a dos motivos circulares - y un segmento de igual diseño para el espacio bajo la llave- inscritos en un plafón cuadrangular cuyos ángulos, rebajados, rellenan hojas de perfil quebrado conseguidas con sencillos golpes de gubia. Si bien es este esquema muy común entre piezas del siglo XVIII, más novedosa es la traza de los motivos circulares, compuestos en su interior por una suerte de tracerías. La otra presenta por toda decoración un sencillo trabajo de talla a bisel con triángulos rehundidos. Obra nueva en ambos casos son los faldones de perfil recortado.

En la estancia que trata de evocar la sala se expone un arca de buena factura. Obra de nogal, con costados, fondo, tapa, trasera y frente (de $57 \mathrm{x}$ $155 \mathrm{~cm}$ ) de una pieza, ensamblada con colas de milano actualmente ocultas por cantonera estriada, sin duda fruto de una intervención posterior, conserva goncios para el movimiento de la tapa y huella de un abisagrado anterior. Sin cerradura actualmente, una pieza de madera tapa el hueco de

${ }^{41}$ Ubicado en la zona centro occidental de Asturias, el concejo de Grado está formado en la actualidad por 28 parroquias y una población que no llega a los 11.000 habitantes (de los cuales más de 7000 viven en la Villa de Grado, que ejerce como capital). Es de justicia dejar constancia de nuestra gratitud a todas las personas que nos facilitaron el acceso a sus piezas con exquisita amabilidad o nos proporcionaron información. 
la que fuera su mortaja. La decoración tallada del frente resulta un buen ejemplo del gusto de la segunda mitad del siglo XvIII. Tres campos cuadrangulares organizan el espacio, dividiéndose a su vez los de los extremos, idénticos, en cuatro para trazar florones de siete hojas lanceoladas, con nervio central y golpes de gubia, que parten de una corola con botón central. El espacio de una octava hoja, siempre orientada al centro, se reserva para una nueva corola común de ocho pétalos. El tramo central, en el que se deja espacio para el escudo de la cerradura, usa de nuevo de las corolas, de relieve más plano en este caso, pero incorpora también motivos nuevos. Conforme a lo expuesto ya en apartado anterior, preside la composición una cruz; doble en este caso, pues una sencilla asentada directamente sobre el borde del frente se ve reforzada por una celdilla de triángulos vaciados a bisel también de diseño cruciforme. El espacio se rellena, en esa búsqueda de riqueza por acumulación que preside el conjunto, con abanicos y rosetas hexapétalas agrupadas dos a dos en torno al cierre, que como se ha señalado también se cuentan entre los motivos más frecuentes del arte popular de toda la Europa agraria y muy especialmente de la atlántica (Fig. 8).

Bien perfiladas, vaciadas con pulcritud, las formas no adquieren gran

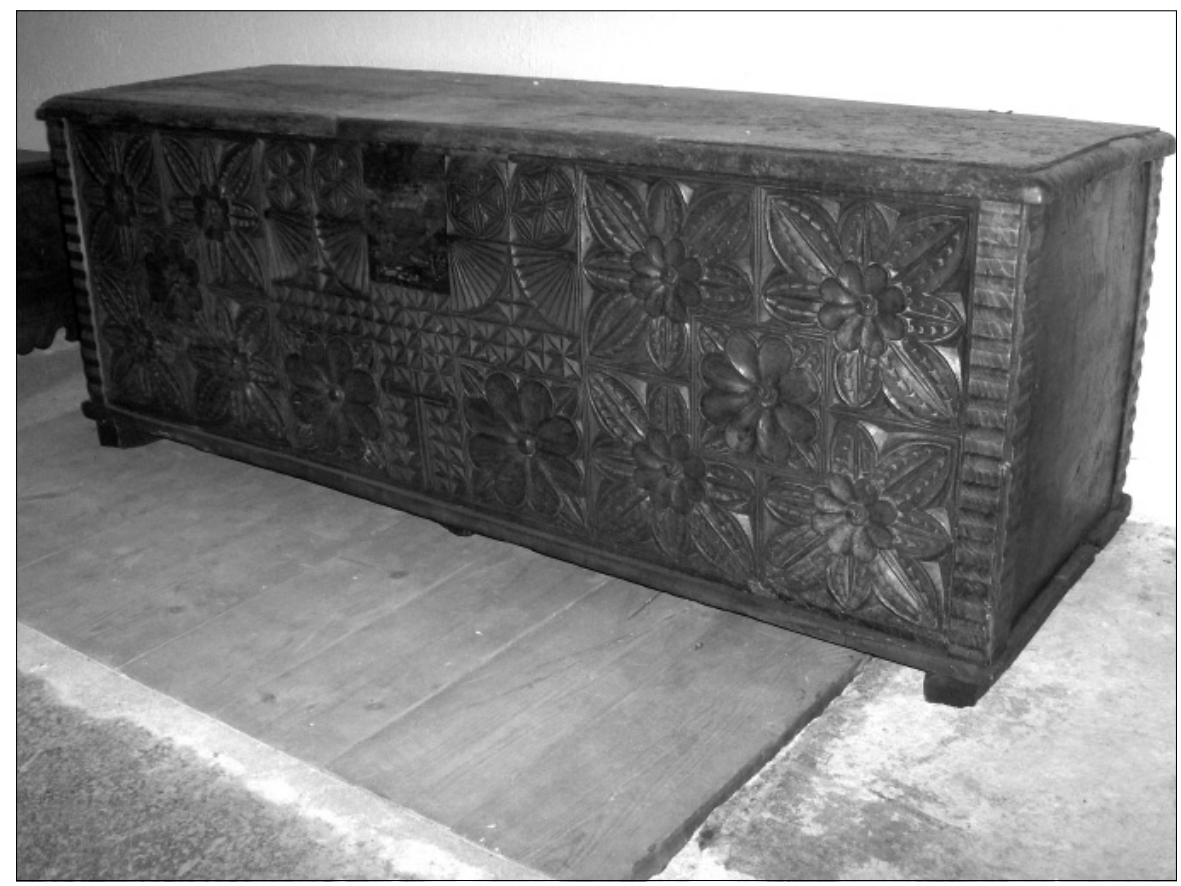

Figura 8. Arca. Museo Etnográfico de Grado, Asturias. Segunda mitad del S. XVIII. 
realce, pero resultan eficaces en la consecución de una idea de riqueza y exuberancia. Es obra muy próxima, si no de la misma mano, al trabajo decorativo de una panera trasladada desde La Granda en el concejo de Llanera a la parroquia de Biedes en Las Regueras, limítrofe con Grado ${ }^{42}$.

Hemos citado ya la existencia también en el museo de un arca de excelente factura que consideramos pieza de procedencia vasca. Anchos montantes se prolongan a modo de patas sobre los que arman los costados - conformados por dos piezas- y el frente, que encaja a su vez sobre faldón recortado. La decoración, de cuidado diseño y ejecución, se vuelca al frente principal, trazando en las patas series de radiales rectos y curvos - alternando dextrosos y sinestrosos - sometidos a enmarques rectos y sencillas orlas de golpes de gubia vaciada. Preside el frente una cruz sobre pie semicircular flanqueada por dos grandes motivos circulares complejos; dobles radiales concéntricos con gallones interiores curvos en movimiento de sentido contrario.

En el palacio que fuera de Miranda-Valdecarzana, actual edificio municipal que alberga distintos servicios culturales, se han quedado presumiblemente varias piezas de su mobiliario original. Nos interesan ahora dos de ellas; un arca de castaño de grandes proporciones (70 x $193 \times 64 \mathrm{~cm}$ ) (Fig. 9), sin decoración labrada, y otra, también de castaño pero con el frente tallado (Fig. 10). La primera, que refuerza con hierros ensambles y clavazón y presenta asas en los costados, parece especialmente adaptada para el transporte y encaja con modelos muy habituales en la zona leonesa. La segunda participa del principio compositivo descrito para la más labrada de las piezas del museo, si bien resolviéndolo con menor calidad de talla y de diseño. Hexapétalas inscritas en círculos y florones de ocho hojas lanceoladas buscan ocupar por completo y de forma simétrica los extremos del frente, trazando en el centro un sencillo abanico y tetrapétalas en varias combinaciones.

Ya en domicilios o colecciones particulares nos encontramos con piezas muy diversas que podrían ejemplificar los distintos tipos de decoración esbozados en el apartado anterior. Hay un conjunto de arcas de factura tosca, bien representado, por ejemplo, en un mueble localizado en Baselgas o en dos piezas de una colección particular en la Villa. El primero (Fig. 11) juega en su frente - tapa y fondo son piezas nuevas- apenas con rosetas hexapétalas y formas circulares concéntricas conseguidas en los motivos de mayor desarrollo con golpes de formón; los mismos que forman la orla perimetral y las barras de enmarque interior. Las segundas combinan motivos circulares y florones de inspiración vegetal, pero resueltos de modo

\footnotetext{
${ }^{42}$ Imágenes de la talla de esta panera pueden verse en Graña (2006: 216).
} 


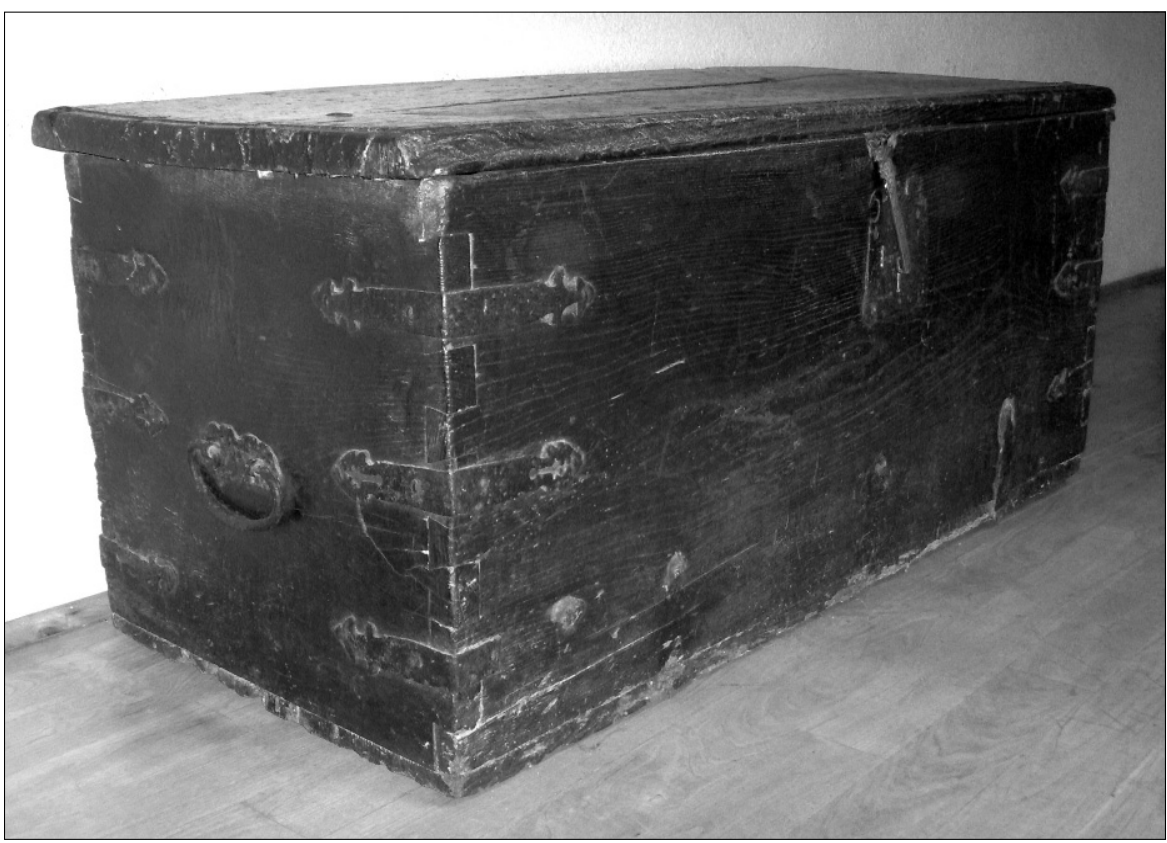

Figura 9. Arca de viaje. Palacio Miranda-Valdecarzana, Grado. Asturias.

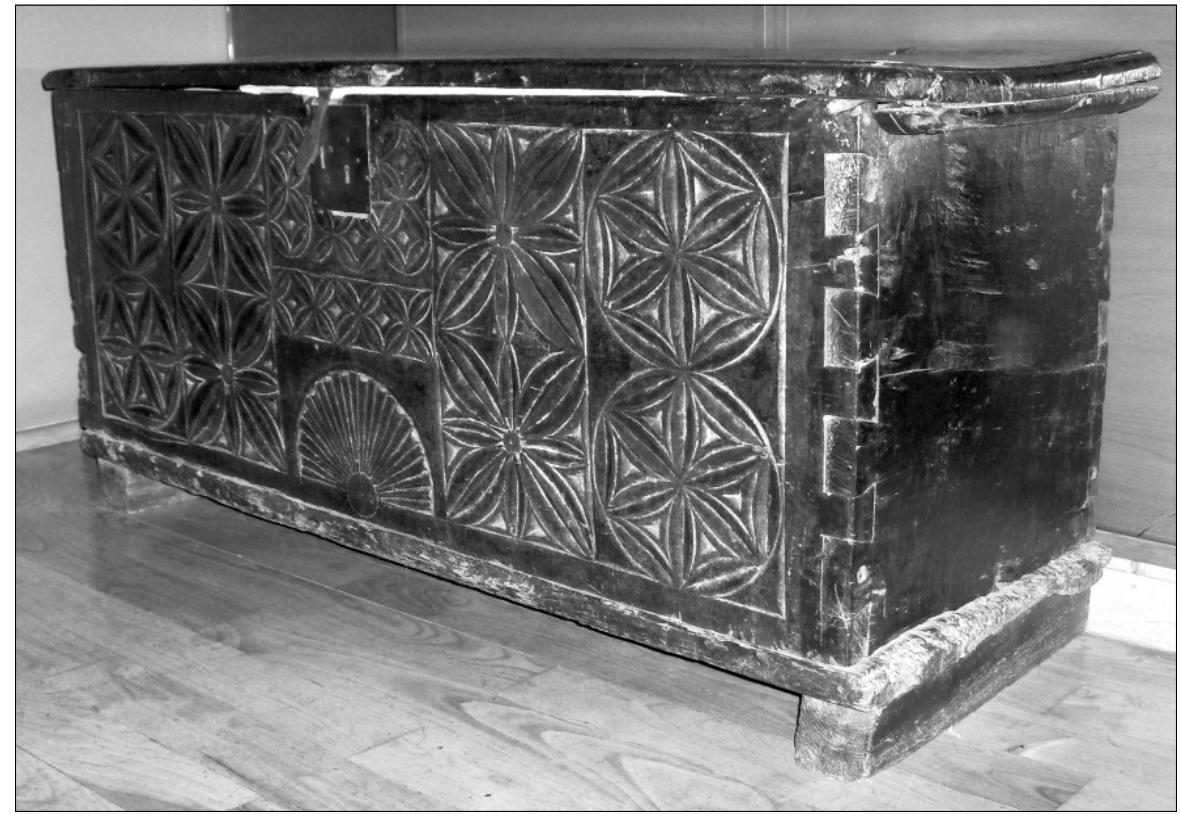

Figura 10. Arca. Palacio Miranda-Valdecarzana, Grado. Asturias. S. XVIII. 


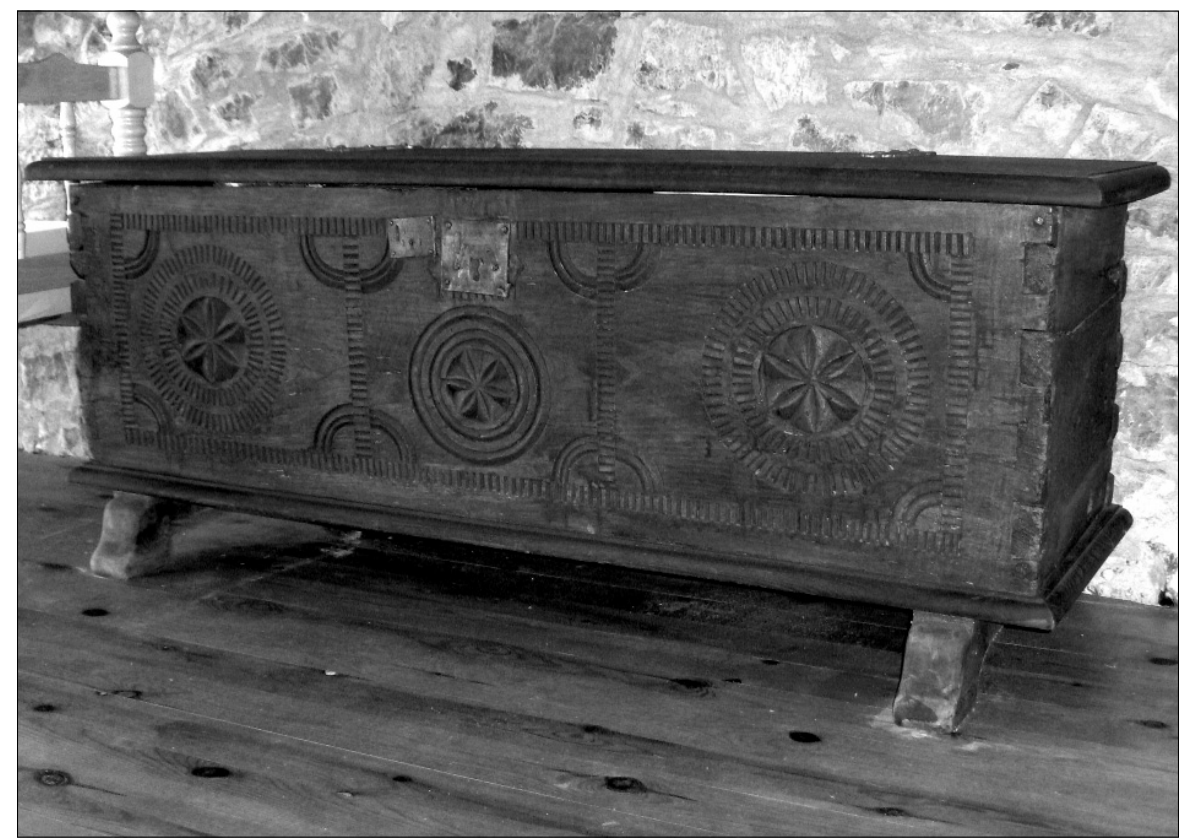

FIguRA 11. Arca. Colección particular, Baselgas. Grado. Asturias.

ingenuo. Poco más que un dibujo inciso hay en una de ellas, dando forma a radiales curvos cuajados en su interior y en el borde del círculo que los encierra de golpes de gubia flameantes dando unas formas muy próximas a las de algunos respiraderos de hórreos de fines del XVII o la primera mitad del XVIII. En la otra (Fig. 12) sorprenden los peculiares radiales rectos con pequeño tetrasquel central o los grandes plafones con segmentos curvos en los ángulos.

Que sencillez en el esquema compositivo y economía técnica y de motivos puede dar resultados más armónicos lo demuestra una arqueta también de Baselgas (Fig. 13). Compuesta en cerezo, parece obra del XVIII que recurre a radiales curvos centrando plafones con los ángulos matados por abanicos para ornar el frente.

Frente a estas obras, un arca de castaño barnizado en tono oscuro mate — que vira con el tiempo a negro y que probablemente trataba de conferir a muebles de calidad la apariencia de nogal— puede ejemplificar la obra de carpinteros especializados o ebanistas locales en la segunda mitad del siglo XVIII (Fig. 14). Medios balaustres torneados ocultan en el frente los ensambles, armonizando las patas con la sinuosidad de su perfil. Molduras sencillas pero labradas con limpieza articulan el frente para enmarcar dos 


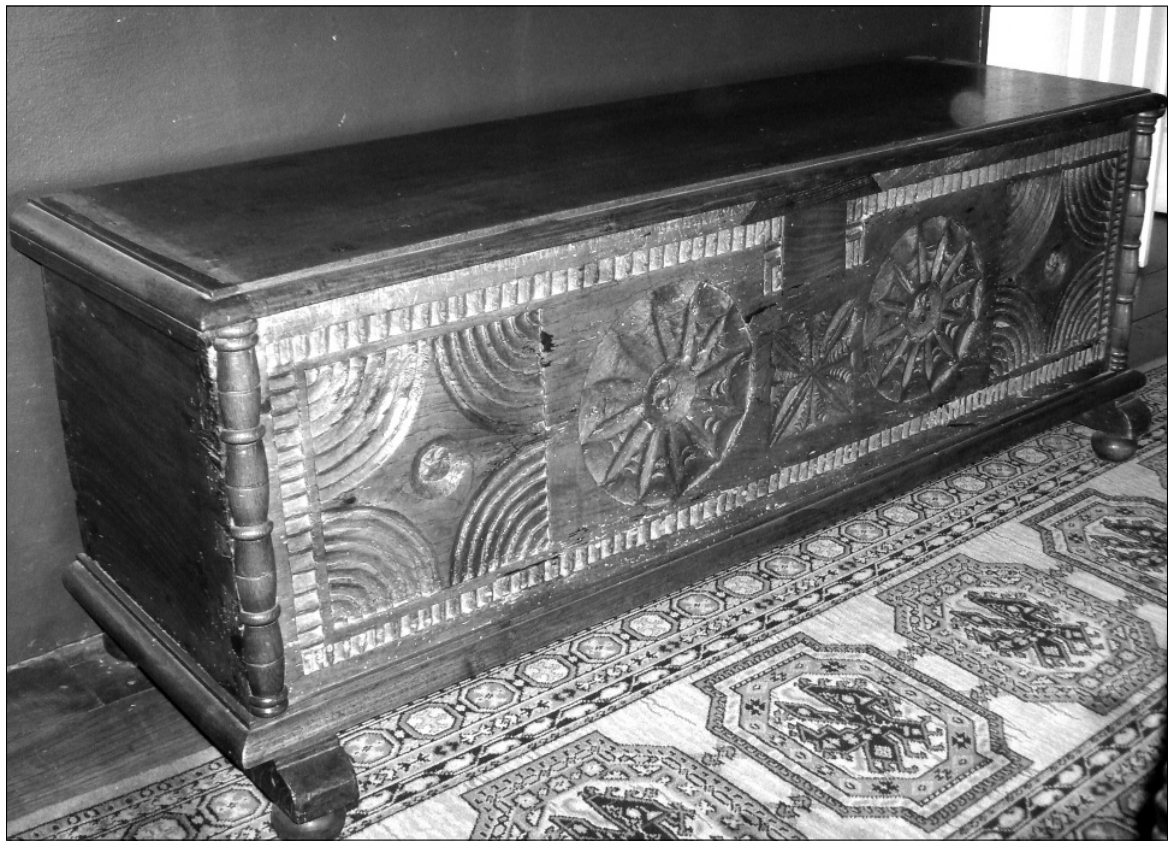

FiguRa 12. Arca. Colección particular, Grado. Asturias.

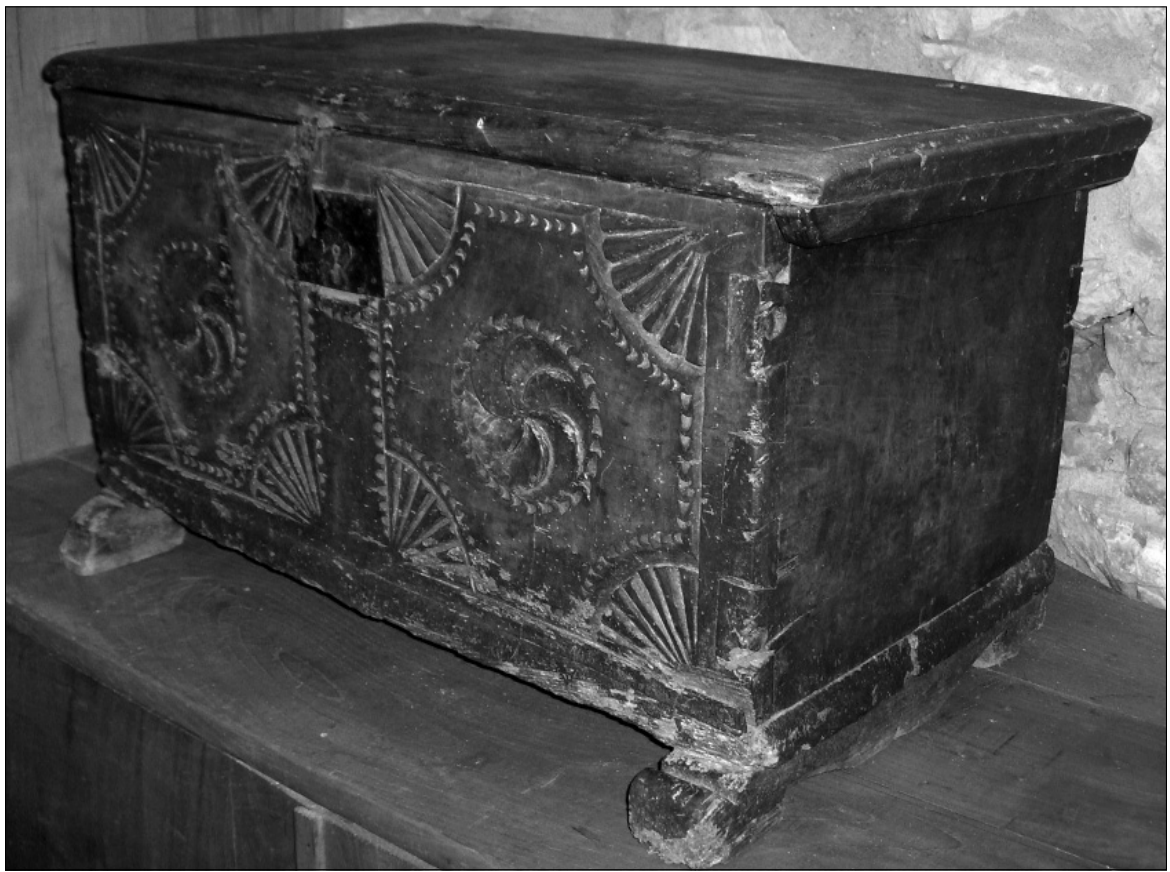

FiguRA 13. Arquilla. Colección particular, Baselgas, Grado. Asturias. 


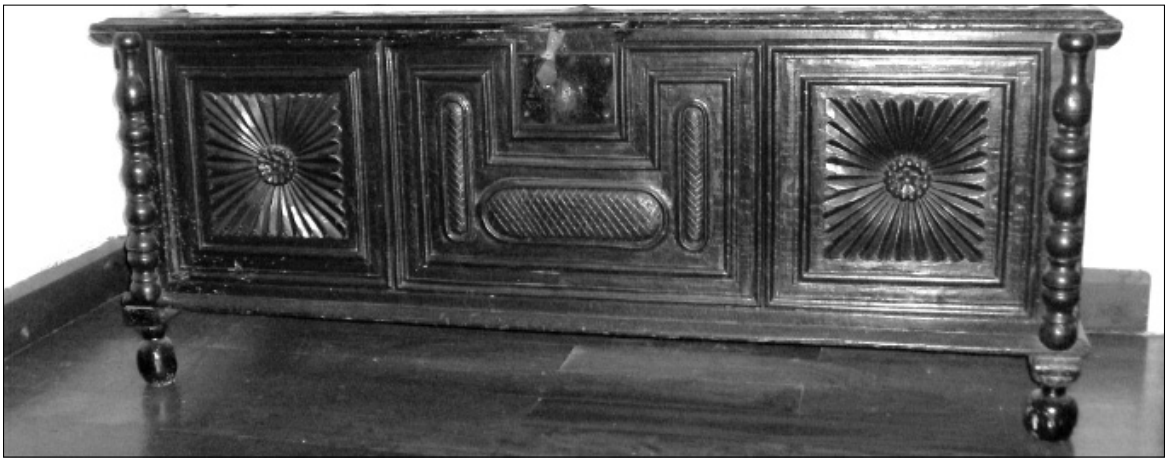

FIgURA 14. Arca. Colección particular, Grado. Asturias. S. XVIII.

plafones cuadrados de estilizados gallones con botón floral y espejos ovales reticulados.

En un término medio, con marcado sabor "popular" pero calidad mayor a los ejemplos comentados al inicio, se situaría un arca fechable en el siglo XVIII y conservada hoy en un palacete burgués de Grado capital y cuyo origen se desconoce. Medios balaustres torneados ocultan nuevamente el engarce a cola de milano, enmarcando el frente. Se articula éste en tres campos regulares, de los cuales el central recibe la bocallave y una hexapétala inscrita en círculo de gran tamaño entre cenefas de picos de diferente resalte. A uno y otro lado, un aspa genera cuatro espacios triangulares que se pueblan con hexapétalas y formas aveneradas. Muy próximas en composición y ejecución —usando también el motivo avenerado, nada frecuente en las arcas asturianas - son las piezas de Casa Xuan Antonio en el Concejo de Gozón (Díaz 2005: 135) y El Valle en Carreño (López y Graña 1988b: fig. 13), sin duda obra de la misma mano.

Pieza excepcional es un arca de taracea, probablemente del siglo XVII, conservada también en un palacete burgués de la Villa (Fig. 15), según información oral del actual propietario, fruto de adquisición a principios de siglo en el mismo concejo. Nogal, limoncillo y boj se emplean para componer los motivos decorativos del frente y los costados, respondiendo estructuralmente al esquema común en Asturias ya descrito ${ }^{43}$.

Una cadeneta de eslabones ovales en cuyo campo interior, oscuro, se recorta en madera clara una estilización vegetal de perfil muy quebrado

${ }^{4}$ La pieza merece un análisis más detenido que permita precisar muchos aspectos, sobre todo de orden técnico y de uso de materiales, que abordaremos tan pronto nos sea posible su acceso. De igual modo, conforme se vaya contando con mayor número de piezas taraceadas localizadas será posible abordar su estudio desde otros ángulos. 


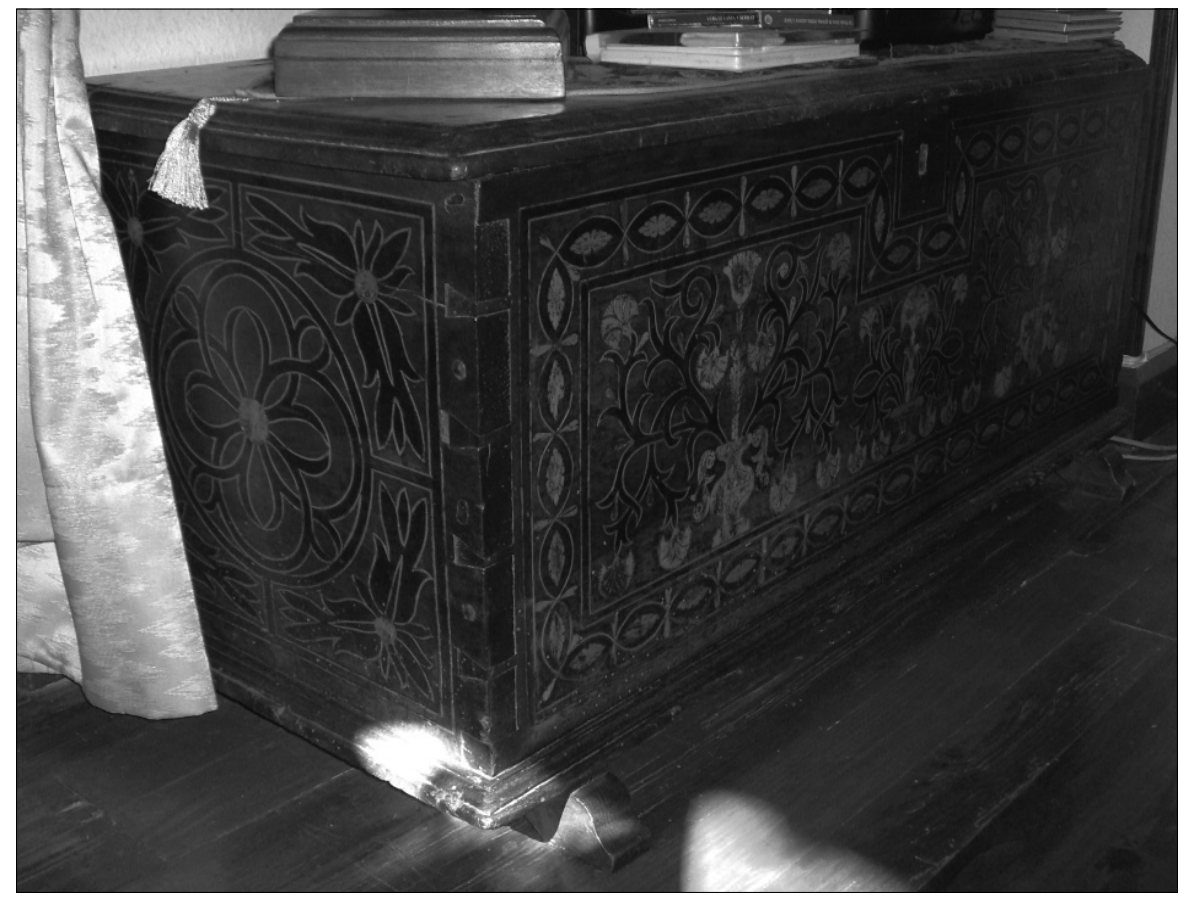

Figura 15. Arca con trabajo de madera embutida. Siglo XVII. Colección Particular, Grado.

funciona como orla de enmarque del frente, recortando conforme al esquema usual el espacio para la cerradura. El campo interior se organiza simétricamente - una simetría estricta regirá la traza de cada uno de los motivos también-, disponiendo un jarrón o cestillo del que emerge un potente tallo de remate floral en abanico —esquematizado pero que recuerda vivamente las formas del clavel- flanqueado por sendos tallos de gran sinuosidad que juegan entre sí solapándose en los cruces y que rematan también en inflorescencias. Este esquema se repetirá a uno y otro lado, aprovechando el mayor espacio de las áreas laterales para trazar jarrones más complejos, estrangulados a la altura del pie y del cuello y con desarrolladas asas. Un sencillo despiece geométrico organiza los costados, segregando un círculo central que ocupará a su vez un motivo circular de gran elegancia, a medio camino entre la estilización vegetal y la geometría. Florones de hojas quebradas se adaptarán al espacio de los ángulos, en esquema muy utilizado en la plástica de la segunda mitad del XVIII.

Una pieza de menor formato, en cuyo frontal aparecen dos de los jarrones más desarrollados usados en este caso, dibujan José Luis y Efrén 
García Fernández (1976: 165) como de "Casa Don Liberto" en la parroquia de Noceda. A pesar de lo sumario del dibujo, parece evidente que son obra de la misma mano.

El estado de la investigación sobre el mueble en Asturias no permite precisar respecto al origen de piezas de estas características o su cronología. Se piensa en la existencia de talleres avezados en el trabajo de la taracea, activos durante el siglo XVII en la zona oriental asturiana y cuyos tipos permanecieron en la centuria siguiente, pero no es posible afinar aún respecto a su relación con los talleres de la zona de Palencia, Burgos o los del valle de Cabuérniga en Cantabria (Aguiló 1993: 102, 103).

Por otra parte, además de arcas, existen — sobre todo vinculados a casonas y palacios asturianos - sillas, bancos, mesas, bufetes y escritorios que participan de esta técnica, que habría que estudiar en conjunto y que constituye uno de los aspectos más interesantes de esa historia del mueble en el Principado aún por hacer.

\section{BIBLIOGRAFÍA CITADA}

Aguiló Alonso, M. P. 1974. "Muebles catalanes del primer tercio del siglo XVI". Archivo Español de Arte 187: 249-271.

Aguiló Alonso, M. P. 1987. El mueble clásico español. Madrid: Cátedra.

Aguiló Alonso, M. P. 1990. "Mobiliario en el siglo XVII", en Mueble español. Estrado y dormitorio: 103-132. Madrid: Comunidad de Madrid.

Aguiló Alonso, M. P. 1993. El mueble en España. Siglos XVI y XVII. Madrid: CSIC y Ed. Antiquaria.

Álvarez Peña, A. 2002. Simbología mágico-tradicional. Gijón: Picu Urriellu.

Artiñano, P. M. 1935. "Los lizos para fabricación de cintas en la región asturiana". Anales del Museo del Pueblo Español I: 68-70.

Cabal, C. 1931. Las costumbres asturianas, su significación y sus origenes. II. La familia, la vivienda, los oficios primitivos. Madrid: s.e.

Caso, F. de; C. Cuenca; C. García de Castro; J. Hevia; V. de la Madrid; G. Ramallo 1999. La Catedral de Oviedo. Catálogo y bienes muebles. (vol. II). Oviedo: Ediciones Nobel.

De la Madrid Álvarez, V. 2005. "El palacio de Miranda-Valdecarnaza y la capilla de Nuestra Señora de los Dolores de Grado". Liño. Revista anual de Historia del Arte 11: 103125. Transcripción del documento: 122-125.

Díaz Quirós, G. (coord.) 2001. Arquitectura popular en Gozón. De casas hórreos y paneras. Aproximación al origen del Estilo Carreño. Heres: Asociación Apolo.

Díaz Quirós, G. 2003. "A propósito de la custodia como motivo decorativo en Hórreos y Paneras de los siglos XVIII y XIX en Asturias", en F. J. Campos (Coord.) Religiosidad y ceremonias en torno a la eucaristía: Vol. 2, 1013-1046. El Escorial: Instituto Escurialense de Investigaciones Históricas y Artísticas.

Díaz Quirós, G. 2005. "Contribución al conocimiento del mobiliario popular asturiano: arcas con decoración tallada en el concejo de Gozón". Liño. Revista Anual de Historia del Arte 11: 127-140. 
Díaz Quirós, G. 2006. "El Estilo Carreño: estado de la cuestión y perspectivas de investigación", en Actas del I Congreso del hórreo asturiano: 115-135. Oviedo: Horru.com.

Díaz Quirós, G. 2007. "Notas sobre mobiliario popular en Asturias: lo que hay y lo que falta", en Actas del I Congreso de Estudios Asturianos. Tomo IV: 307-322. Oviedo: RIDEA.

Escortell Ponsoda, M. 1984. Catálogo de la colección etnográfica del Museo Arqueológico. Oviedo: Consejería de Educación, Cultura y Deportes del Principado de Asturias.

Feduchi, L. 1986 [1949] Historia del Mueble. Barcelona: Blume.

Ferreiro, J. L. 1931. "Les instruments en bois decorés des provinces asturiennes", en $I$ Congrés Internacional des Arts Populaires: 202-203. París.

Friera Suárez, F. 2007. "Los hermanos Pruneda en las artes del siglo XVIII", en Actas del I Congreso de Estudios Asturianos. Tomo V: 51-76. Oviedo: RIDEA.

García de Castro, C. 1999. "Arca Santa (1075-1109)", en La Catedral de Oviedo, II Catálogo y bienes inmuebles: 43-46. Oviedo: Ediciones Nobel.

García Fernández, E.; J. L. García Fernández; C. Fernández B. De Quirós 1976. El Camino Real del Puerto de la Mesa. Oviedo: Colegio Oficial de Arquitectos de León y Asturias.

González Calle, J. A. 2001. La nobleza en Asturias durante la Baja Edad Media. Génesis y evolución de linajes representativos. Universidad de Oviedo. Tésis doctoral inédita.

González Calle, J. A. 2002. "Horros y paneres decoraos nel conceyu de Corvera". Asturies, memoria encesa d'un país 14: 52-70.

González Menéndez, L. 1998. La colección de Artes Decorativas de la Fundación SelgasFagalde. Cudillero: Fundación Selgas-Fagalde.

Graña García, A. 1997. "Cunas del siglo XIX". Nuestro Museo: Boletín Anual del Museo Arqueológico de Asturias 1: 87-90.

Graña García, A. 2006. "Materiales para el estudio del arte popular en Asturias: hórreos y paneras decoradas en el concejo de Las Regueras", en Estudios ofrecidos a José Manuel González: 205-239. Las Regueras: La Piedriquina.

Hevia Llavona, I. 2004. Les paneres de Maliayo. Gijón: Vtp editorial.

Jorge Aragoneses, M. 1954. "Las artes de la madera en España", R.A.B.M., T.LX: 605-629.

Krüger, F. 1959. "El mobiliario popular en los países románicos". Anales del Instituto de Lingüística VII. Mendoza: Universidad Nacional de Cuyo.

Krüger, F. 1963. El mobiliario popular en los países románicos. Suplemento III da Revista Portuguesa de Filología. Coimbra: Facultade de Letras da Universidade de CoimbraInstituto de Estudios Románicos.

Lago Mediante, P. 1988. "Mobiliario y ajuar", en Enciclopedia Temática de Asturias. 8, Etnografía y folklore I: 115-126. Gijón: Silverio Cañada Editor.

López Álvarez, J. y A. Graña García 1983. Hórreos y paneras del concejo de Allande (Asturias) Evolución y motivos decorativos. Oviedo: Biblioteca Popular Asturiana.

López Álvarez, J. y A. Graña García 1985. "Aproximación a los estilos decorativos de los hórreos y paneras asturianos". Ástura. Nuevos cortafueyos d'Asturies 4: 55-72.

López Álvarez, J. y A. Graña García 1986. "Materiales para el estudio del mobiliario en Asturias, I.: Las arcas de tres llaves". Ástura. Nuevos cortafueyos d'Asturies 5: 25-31.

López Álvarez, J. y A. Graña García 1988a. "Arte popular en madera y piedra", en Eciclopedia Temática de Asturias. 9, Etnografía y Folklore II: 123-134. Gijón: Silverio Cañada Editor.

López Álvarez, J. y A. Graña García 1988b. "Materiales para el estudio del mobiliario en Asturias, II: Arcas con decoración tallada". Revista de Dialectología y Tradiciones Populares XLIII: 331-343. 
López Álvarez, J. y A. Graña García 1996. "Arte mueble y talla popular", en El arte en Asturias a través de sus obras: 667-690. Oviedo: Editorial Prensa Asturiana.

López Álvarez, J. y A. Graña García 2005. "El mobiliario en la casa asturiana", en Los asturianos. Raices culturales y sociales de una identidad: 146-160. Oviedo: Editorial Prensa Asturiana.

Llano, A. de. 1922. Del folklore asturiano. Mitos, supersticiones, costumbres. Madrid: Talleres de Voluntad.

Manso De Zúñiga, J. 1962. "Las kutxas de caballos". Boletín de la Real Sociedad Vascongada de Amigos del País, año XVIII: 352-359.

Mases, J. A. 1994. "La casa campesina", en Enciclopedia de la Asturias Popular. 49-64. Oviedo: La Voz de Asturias.

Moya Valgañón, J. G. 1990. "Un siglo de historiografía del mueble español", en Mueble español. Estrado y dormitorio: 11-23. Madrid: Comunidad de Madrid.

Piera, M. y A. Mestres 1999. El mueble en Cataluña. El espacio doméstico del gótico al modernismo. Barcelona: Fundació Caixa Manresa.

Ramallo Asensio, G. 1999. "El Renacimiento y el Barroco. Catálogo y bienes muebles", en La Catedral de Oviedo. II. Catálogo y bienes muebles: 270-286. Oviedo: Nobel.

Torrente Fernández, I. 1982. El dominio del monasterio de San Bartolomé de Nava (siglos XIII-XVI). Oviedo: Universidad de Oviedo.

Sanz Fuentes, M..$^{\mathrm{a}}$ J. 2008. "Un armador de pesca en Candás a comienzos del siglo XVII: Bastián García de Folguera". Portfolio de las fiestas del Stmo. Cristo de Candás, n. XLIII: 110-112.

Fecha de recepción: 2 de diciembre de 2008

Fecha de aceptación: 12 de mayo de 2009 